ISSN: 0213-2052 - eISSN: 2530-4100

DOI: http://dx.doi.org/10.14201/shha20193795130

\title{
JUVENTUD Y ADOLESCENCIA EN LAS VIDAS PARALELAS DE PLUTARCO. ALGUNAS NOTAS HISTORIOGRÁFICAS ${ }^{1}$
}

\section{Youth and Adolescence in Plutarch's Parallel Lives. Some Historiographical Notes}

\author{
Borja MÉNDEZ SANTIAGO \\ Universidad de Oviedo \\ mendezsborja@uniovi.es
}

Fecha de recepción: 17-10-2018; aceptación definitiva: 5-3-2019

RESUMEN: El presente estudio pretende, a partir de un análisis preliminar del tratamiento de la juventud en las Vidas Paralelas, ofrecer una primera aproximación a la juventud en Plutarco como objeto de estudio de pleno derecho. Para ello, tras destacar la importancia de este tipo de análisis, y tras exponer algunos de los postulados básicos que guiarán el presente trabajo, se analizarán, de manera breve, los principales referentes historiográficos para el estudio de las primeras franjas etarias de la vida en la antigüedad grecorromana. A continuación, realizaremos un acercamiento a la juventud a través de la lente de los autores antiguos, el cual destacará las ambigüedades y ambivalencias atribuidas a este grupo de edad,

1. Este texto se inscribe dentro del marco del Proyecto I+D+I de Excelencia del Ministerio de Economía y Competitividad titulado Maternidades, filiaciones y sentimientos en las sociedades griega y romana de la Antigüedad. Familias alternativas y otras relaciones de parentesco fuera de la norma [Ref. HAR2017-82521P], dirigido por la profesora Rosa María Cid López. 
situado a medio camino entre la irracionalidad intrínseca de la infancia y la sensatez que se presupone en las personas adultas. Finalmente, y a través sobre todo de una serie de casos seleccionados por su especial importancia dentro de la enorme colección de anécdotas de las Vidas Paralelas, se intentará insertar la imagen de la juventud ofrecida por Plutarco en su obra biográfica dentro de esa panorámica general, para concluir que, especificidades aparte, el modo de pensar de nuestro autor coincide, en rasgos generales, con el de la mayor parte de los escritores de su tiempo ${ }^{2}$.

Palabras clave: Vidas paralelas; agencia; panorámica historiográfica; anécdotas.

ABSTRACT: The present study pretends, from a preliminary analysis of the treatment of youth age in the Parallel Lives, to offer a first approach to the youth in Plutarch as a study object in its own right. For that, after highlighting the importance of this kind of studies, and after exposing some of the basic postulates which will guide this text, the main historiographical referents to the study of the first age-stages in the Greco-Roman antiquity will be analyzed. Then, we will approach the youth through the lens of the ancient authors, by which we will highlight the ambiguities and ambivalences attributed to this age-group -situated halfway between the intrinsic irrationality of the infancy and the prudence that is presupposed to the adult people-. Finally, and mainly by using some references selected for its special relevance inside the huge collection of anecdotes in the Parallel Lives, we will try to include the image of the youth given by Plutarch in his biographical writings inside this perspective, watching that, specificities apart, the way of thinking of our author coincides, in general features, with that of most of the writers of his time. dotes.

Keywords: Parallel Lives; Agency; historiographic panoramic; anec-

\section{INTRODUCCIÓN}

La producción científica en torno a la figura de Plutarco y los variados aspectos de su obra es hoy ciertamente abrumadora, y resulta imposible, incluso para el especialista, estar familiarizado con todos los trabajos que se han ido acumulando durante el transcurso de los últimos treinta años, desde que en diversos países, entre ellos España, se han ido

2. Por regla general, y si no se indica expresamente lo contrario, las citas en griego y en latín proceden de las ediciones bilingües de la Loeb Classical Library; las traducciones de estos textos al castellano han sido extraídas de la Biblioteca Clásica Gredos. 
constituyendo asociaciones muy activas de plutarquistas. Sin embargo, resulta sorprendente la escasa atención que los estudiosos han otorgado a un aspecto que me parece central a la hora de comprender las dinámicas que operan en el centro de las Vidas. Me refiero, cómo no, a las distintas franjas etarias en las que se divide la existencia de los personajes que pueblan las biografías plutarquianas, las cuales merecen, en mi opinión, un estudio específico ${ }^{3}$.

Debido a las enormes dimensiones de la obra del polígrafo de Queronea, este artículo tan solo pretende centrarse en algunas de las características generales con las cuales es presentada la juventud masculina, como colectivo de edad específico, dentro de las Vidas Paralelas ${ }^{4}$. Pero, antes de abordar este tema me parece necesario realizar una serie de consideraciones previas que, extendiéndose durante los dos próximos epígrafes buscarán, respectivamente, realizar un breve recorrido por la historiografía relativa a la infancia y la juventud en el mundo grecorromano -a través, sobre todo, de una conocida polémica- y presentar varios de los rasgos generales con los cuales los autores griegos y latinos caracterizaron a los más jóvenes de su tiempo.

3. En los últimos veinte años, se han realizado algunas aportaciones interesantes sobre el tema de las franjas etarias en la obra de Plutarco, algunas veces adoptando una perspectiva más general (vid. SOAREs, Carmen: Crianças e jovens nas Vidas de Plutarco. Coimbra, 2011), y otras a través de casos de estudio específicos (vid. Bradley, Keith: "Images of Childhood - The Evidence of Plutarch", en Pomeroy, Sarah (ed.): Advice to the Bride and Groom and A Consolation to His Wife: English Translations, Commentary, Interpretative Essays, and Bibliography. Oxford, 1999, pp. 183-196, o el más reciente OliveIra, Loraine: "O jovem Teseu: do reconhecimento paterno ao reconhecimento político", en Gómez Cardó, Pilar, Leão, Delfim F. y De OliveIRA Silva, Maria Aparecida (coords.): Plutarco entre mundos: visões de Esparta, Atenas e Roma. Coimbra, 2014, pp. 31-48).

4. Soy perfectamente consciente de la importancia que tienen, para el estudio de la misma, ciertos tratados dentro de los Moralia que han tenido que ser aquí soslayados, como Del amor fraterno, Del amor a la prole, De si puede enseñarse la virtud, Consolación a la esposa, Charlas de sobremesa, Sobre si el anciano debe intervenir en la politica y De la educación de los niños, obra que la mayor parte de la crítica estima que no fue escrita por Plutarco, sino por otro autor diferente, que es llamado convencionalmente "Pseudo-Plutarco". Para una explicación convincente de las razones que han llevado a esta obra a ser atribuida a otro autor distinto de Plutarco, véase Xenophontos, Sofía: "Plutarch", en Bloomer, Martin W. (ed.): A Companion to Ancient Education. Malden/Oxford/West Sussex, 2015, pp. 335-346. Para una interpretación de los Moralia como marco teórico ideal de referencia y de las Vidas como el lugar donde estos ideales debían ponerse (o no) en práctica, vid. Teodorsson, Sven-Tage: "The Education of Rulers in Theory (Mor.) and Practice (Vitae)", en Nikolaidis, Anastasios, G. (ed.): The Unity of Plutarch's Work: Moralia themes in the Lives, Features of the Lives in the Moralia. Berlin-New York, 2008, pp. 339350 . 
Autores tan importantes como Keith Bradley afirmaron que, en las $\mathrm{Vi}$ das Paralelas, la infancia -y, añadiría yo, la juventud-, interesan solamente en su faceta de preparación para la vida pública adulta ${ }^{5}$. Aun siendo tal extremo completamente cierto, desde aquí se defenderá la importancia intrínseca del análisis de estas franjas etarias, puesto que, según autores como Cicerón ${ }^{6}$ y Séneca, cada una de ellas tenía su propia constitutio ${ }^{7}$; es decir, a cada una de ellas se atribuían unas determinadas características definitorias. Así, para Cicerón, la infirmitas sería propia de los niños, la ferocitas de la juventud, la gravitas de la edad adulta y la maturitas de la ancianidad ${ }^{8}$. En el último apartado de este trabajo veremos algunas formas en que esa ferocitas se manifiesta dentro de las Vidas?.

Una de las mayores complicaciones a la hora de estudiar la infancia y la juventud en la antigüedad radica en la terminología empleada por los propios autores griegos y latinos a la hora de hacer referencia a las distintas divisiones etarias. Así, por ejemplo, Plutarco, para aludir a niños y jóvenes, utiliza, según Carmen Soares, hasta diez términos diferentes: brephos (bebé), nepios (niño/a pequeño/a), paidion (niño que se puede llevar al cuello), paidarion (término que se refiere desde a bebés hasta niños de cuatro o cinco años), pais (vocablo sumamente amplio, que puede hacer referencia, indistintamente, a un niño o a un adolescente, y que también es utilizado para hacer alusión a la filiación), antipais (referente al niño que ha llegado hace poco a la adolescencia), meirakion (término asociado a la fuerza física, y que generalmente alude a individuos que acaban de llegar a la edad mínima en la que se pueden enrolar al ejército), neos, neanias-neaniskos (términos que expresan genéricamente juventud)

5. Vid. Bradley, Keith: "Images of childhood...", op. cit., pp. 185-186.

6. Cicerón, Sen. 10, 33: Cursus est certus aetatis et una via naturae, eaque simplex, suaque cuique parti aetatis tempestivitas est data, ut et infirmitas puerorum, et ferocitas iuvenum et gravitas iam constantis aetatis et senectutis maturitas [...].

7. Séneca, Ep. 121, 15: Unicuique aetati sua constitutio est, alia infanti, alia puero, alia seni; omnes ei constitutioni conciliantur in qua sunt [...].

8. Para mayores precisiones, cf. López GREGoris, Rosario: "La infancia en Roma", en Hernández Crespo, Rosa M. y Domínguez Monedero, Adolfo J. (eds.): Las edades del hombre. Las etapas de la vida entre griegos y romanos. Madrid, 2014, pp. 69-91.

9. Otros autores de la antigüedad, como Solón, Varrón, Macrobio, Horacio, Ptolomeo o Diógenes Laercio también elaboraron sus propias teorías acerca de los distintos ciclos en los que se dividía la vida. Para un análisis más detallado de estas fuentes, vid. LaEs, Christian, y StRubBe, Johan: Youth in the Roman Empire. The Young and the Restless Years? Cambridge, 2014, pp. 25-28. 
y ephebos (vocablo que se refiere, más que a una edad específica, a la etapa que sigue a la infancia y que llevará al individuo hasta la edad adulta ${ }^{10}$. Sin embargo, pese a todos los intentos de sistematización que se han realizado, lo cierto es que los términos asociados a cada uno de los grupos de edad apenas mencionados no se aplican, ni siquiera, de una manera uniforme. Así, dentro de las Vidas, he encontrado el uso de estos términos asociados a individuos que no consideraríamos jóvenes en absoluto. Así, por ejemplo -la lista no pretende ser exhaustiva-, en Art. 28, 1, Darío, el hijo de Artajerjes, es caracterizado como "joven" ( $\nu \varepsilon \alpha v i \sigma \kappa \omega)$ a pesar de que, anteriormente, Plutarco nos había dicho de él que tenía cincuenta años

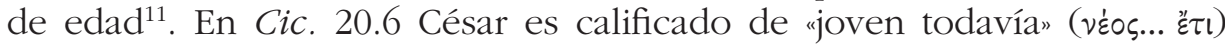

10. Para mayores precisiones, y para ejemplos sobre el uso particular de estos términos dentro de las Vidas Paralelas, vid. SOARes, Carmen: Crianças e jovens..., op. cit., pp. 14-25. Entre los numerosos autores que han centrado sus análisis en el estudio de la terminología empleada para aludir a estas franjas etarias, véanse, sobre todo, SLUSANSKI, Dan: "Le vocabulaire latin des gradus aetatum", Revue Roumaine de Linguistique, 19, 1974, 103-121; NÉRAudau, Jean-Pierre: La jeunesse dans la littérature et les institutions de la Rome républicaine. Paris, 1979, pp. 97-104; Golden, Mark: Childhood in Classical Athens. Baltimore, 1990, pp. 12-22; EyBEN, Emil: "Children in Plutarch", en VAN Der STOcKT, Luc (ed.): Plutarchea Lovaniensia: a miscellany of Restless Youth in Ancient Rome. Essays on Plutarch. Leuven, 1996, pp. 80-82; Harlow, Mary y LAURENCE, Ray: Growing Up and Growing Old in Ancient Rome. A Life Course Approach. London, 2002, pp. 15-17, y RAwson, Beryl: Children and Childhood in Roman Italy. Oxford, 2003, pp. 134-145, quien afirma que, por ejemplo, los romanos no dispusieron de demarcaciones etarias rígidas hasta la tardoantigüedad, ajustándose, por ello, a la hora de otorgar funciones y responsabilidades a los individuos, más a su desarrollo físico y a su capacidad percibida (sobre este aspecto, vid. n. 29). Para un convincente intento por distinguir los distintos términos empleados para aludir a la juventud griega (con las subsiguientes diferencias en derechos y obligaciones), véase Chankowski, Andrzej S.: L'éphébie hellénistique. Étude d'une institution civique dans les cités grecques des îles de la Mer Egée et de l'Asie Mineure. Paris, 2010. En la página 249 de este estudio se afirma, al hilo de los términos etarios empleados en el contexto del gimnasio, que mientras que el vocablo ephèboi es «rigoureux et technique, désignant toujours le même groupe de jeunes" (aquellos que se encontraban realizando ese servicio cívico que, según los sistemas de las distintas póleis, duraba entre uno y tres años), los términos neoi y neaniskoi son mucho más vagos, pudiendo aludir simplemente -y desde un punto de vista general- a aquellos jóvenes que forman parte de la comunidad del gimnasio (paides, neoi/neaniskoi, ephéboi; pp. 253-259) o, más específicamente, a aquellos jque se sitúan en una franja etaria superior a la de los epheboi (pp. 259-264) y que se extendería hasta que alcanzaran los treinta años de edad. Para otro estudio muy interesante en el que se han recogido los términos utilizados no solo para designar a los efebos, sino también aquellos relacionados con los distintos sistemas de entrenamiento ciudadanos en el ámbito cultural helenístico, véase Kennell, Nigel M.: Ephebeia. A Register of Greek Cities with Citizen Training Systems in the Hellenistic and Roman Periods. Hildesheim, 2006.

11. En mi opinión, y a modo de hipótesis de trabajo, este uso concreto del término se encuentra estrechamente relacionado con la manipulación de Darío por parte de Tiríbazo, 
pese a contar ya con treinta y siete años. Por último, en Fab. 24, 1-24, 4 se califica al hijo de Fabio Máximo, de igual nombre, -que ya ostentaba el consulado y que, por consiguiente, debía de rondar los cuarenta años-, de

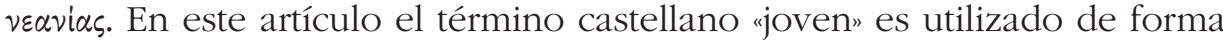
genérica para hacer alusión a individuos cuyas edades oscilan, aproximadamente, entre los doce y los treinta años ${ }^{12}$. Sin embargo, siempre que ha sido posible se ha indicado el término griego concreto utilizado por Plutarco para marcar la edad del individuo. Con todo, debe destacarse una vez más la enorme indeterminación etaria que se detecta en esta colección de biografías; así, en muchos casos, desconocemos la edad exacta de los personajes a los que se alude.

Este interés por la juventud viene a insertarse dentro de una línea de análisis científico que, partiendo del pionero estudio sobre la educación de Henri Marrou (1949), se ha ido desarrollando enormemente hasta alcanzar una producción ingente, tanto en la forma de libros y capítulos de libros como de artículos científicos. Sin embargo, lo que en su momento fue un estudio innovador ahora representa el acercamiento tradicional al tema, y nuevas corrientes historiográficas, desarrolladas sobre todo en el mundo universitario anglosajón, holandés, belga y alemán, han cogido el relevo, primando nuevos temas a través del surgimiento de nuevas inquietudes. Trataremos de dar cuenta de los avances producidos a continuación.

\section{La juventud en la antigüedad I. Brevísima historia de un debate HISTORIOGRÁFICO}

Los primeros estudios relevantes en torno a la infancia y la juventud en la antigüedad beben, incontestablemente, de las metodologías de análisis propuestas por dos autores en sendas obras clásicas. Los modelos de Philippe Ariès ${ }^{13}$ y Lawrence Stone ${ }^{14}$ se convirtieron en los cimientos en los que se sustentaron buena parte de las primeras obras que analizaban todas estas temáticas de historia social dentro de la antigüedad. Una de las máximas compartidas por estos dos autores pasaba por considerar que

sátrapa y general persa que le convenció para participar en una conspiración para acabar con su padre Artajerjes.

12. Las excepciones a este uso general serán debidamente señaladas.

13. ARIÈs, Philippe: L'enfant et la vie familiale sous l'Ancien Régime. Paris, 1960 [hay trad. española, El niño y la vida familiar en el antiguo régimen. Barcelona, 1987].

14. STONE, Lawrence: The Family, Sex and Marriage in England 1500-1800. London, 1977 [hay trad. española, Familia, sexo y matrimonio en Inglaterra 1500-1800. México, 1979]. 
el llamado "nacimiento de la infancia" solamente había tenido lugar hacía unos 250 años, siendo este uno de los cambios más espectaculares acaecidos durante la Ilustración.

Como resulta lógico, los estudiosos dedicados a la antigüedad se apresuraron, ante el éxito de las citadas monografías, a comprobar, a través de sus propias fuentes, si lo afirmado por Ariès y Stone encontraba también aplicabilidad práctica en sus campos de estudio. Del desarrollo de estas primeras investigaciones saldría una de las mayores polémicas historiográficas en el plano de los estudios sobre la infancia y la juventud dentro de la antigüedad grecorromana. Así, mientras algunos autores como Pleket ${ }^{15}$ y su discípulo Kleijwegt ${ }^{16}$ afirmaban que en las antiguas sociedades griega y romana la infancia no era estimada en sí como una etapa independiente de la vida, otros autores -encabezados por Emil Eyben- ${ }^{17}$, consideraron que esto no había sido así, defendiendo por tanto la existencia de una perceptible diferenciación de franjas etarias en los mundos griego y romano de la antigüedad. Antes de enunciar algunas de las deficiencias detectadas por autores más modernos respecto a estos trabajos, quisiera detenerme, si bien brevemente, en explicar algunas de sus ideas clave.

Eyben defendía la existencia de un "no-man's land" entre la infancia y la edad adulta. Para él, los jóvenes $\operatorname{romanos}^{18}$ permanecían en un estado de relativa inactividad desde que tomaban la toga viril (a los quincedieciséis años de edad) hasta los treinta años, momento en el que podían acceder al senado y a las llamadas magistraturas superiores ${ }^{19}$. De acuerdo con este punto de vista no era extraño que Eyben viera (o quisiera ver) en los jóvenes romanos de época tardorrepublicana un gran sentimiento de frustración. A consecuencia de esta idea, la imagen general que se ofrece -basada fundamentalmente en el análisis de unas fuentes literarias latinas

15. Pleket, Henri W: "Licht uit Leuven over de Romeinse jeugd?", Lampas, 12 (1979), 183-192.

16. Kleijwegt, Marc: Ancient Youth: The Ambiguity of Youth and the Absence of Adolescence in Greco-Roman Society. Amsterdam, 1991.

17. Eyben, Emil: Restless Youth in Ancient Rome. London, 1993.

18. En general, en estas primeras obras sobre la juventud en la antigüedad los estudiosos tendían a no enunciar suficientemente que la realidad que ellos abordaban en sus trabajos era solo la de una élite económico-social cuyos rastros se podían seguir tanto a través de la literatura como de los testimonios epigráfícos.

19. Vid. Eyben, Emil: "Was the Roman "Youth" an Adult Socially?", L'Antiquité Classique, 50.1-2, 1981, pp. 328-350. Para la referencia al "no man's land", vid. p. 329. En la p. 340, en parte para contestar los argumentos de Pleket, Eyben se limita a afirmar que también en la antigua Grecia era necesario que "pasara un considerable plazo de tiempo antes de que un hombre fuera considerado capaz de desempeñar una responsabilidad real en la sociedad" (la traducción es mía). 
que abarcaban un enorme espacio cronológico- es que la juventud era un período vital sumamente problemático por contestatario, y en la cual dominaba el conflicto. La ambivalencia mostrada por las fuentes clásicas en relación a esta franja etaria quedaría pues, en opinión de este autor, más que justificada.

Kleijwegt, el mencionado discípulo de Pleket, se adentró en el tema que nos ocupa mucho más profundamente que su maestro. Siguiendo los postulados de Philippe Ariès y Lawrence Stone, y con el objetivo principal de contestar a Eyben ${ }^{20}$, defendió que, en la antigüedad grecorromana, no existió la juventud como etapa vital diferenciada. A su modo de ver, los jóvenes griegos y romanos de la antigüedad -en comparación con los actuales- no necesitaban de un período de preparación tan largo a la hora de poder ejercer las funciones que se esperaba de ellos como adultos. Así, estos jóvenes no serían muy distintos de los adultos en la forma en que participaban en la sociedad o en las funciones que desempeñaban en el seno de la misma ${ }^{21}$. Como base de su estudio, el autor hizo un uso extensivo tanto de las inscripciones epigráficas como de los estudios comparados, a través de los cuales consiguió encontrar numerosos paralelos para sus teorías.

En la actualidad, la moderna historiografía sobre la infancia y la juventud en la antigüedad sigue, en mayor o menor medida, los postulados de ambos estudiosos, aunque no ha dudado a la hora de criticarlos. En lo referente a las afirmaciones de Eyben, resulta muy difícil sostener que la sociedad romana $-\mathrm{O}$ cualquier sociedad preindustrial, en definitiva- pudiera permitirse el lujo de prescindir de los jóvenes pertenecientes a la élite, y máxime relegándoles a una vida inactiva que no los preparara para las futuras acciones que habrían de desempeñar ${ }^{22}$; para Eyben, un varón

20. Kleijwegt, Marc: Ancient Youth, op. cit., pp. 120-121 termina afirmando sobre el trabajo de Eyben que, "aunque la imagen general no sea errónea del todo, es incompleta" (la traducción es mía). Nos encontramos ante un perfecto exponente de los llamados "textos militantes", caracterizados por su dogmatismo a la hora de contestar a todos aquellos estudiosos que defienden tesis opuestas a las que ellos exponen.

21. Ibid., p. 25. Partiendo de este punto de vista, Francesca Mencacci ha llegado a afirmar, de manera un tanto desafortunada, que mientras que los jóvenes pertenecientes a las élites sociales no podían gozar de una larga infancia -de acuerdo con las funciones que deben desempeñar en la sociedad-, la infancia de los niños esclavos sí podría extenderse más en el tiempo. Vid. Mencacci, Francesca: "Modestia vs. Licentia. Séneca on Childhood and Status in the Roman Family", en Dasen, Véronique, y SpÄTH, Thomas (eds.): Children, Memory, and Family Identity in Roman Culture. Oxford, 2010, pp. 223-244 (para la afirmación citada, vid. pp. 238-239).

22. El propio Eyben ya era consciente de la debilidad de su argumento. Por ello, y para tratar de sostenerlo frente a la evidencia incontestable de la existencia de una serie de 
perteneciente a la aristocracia tan solo entraba plenamente en la edad adulta una vez que se casaba y entraba en el Senado ${ }^{23}$. Otra de las críticas que se le ha hecho radica, precisamente, en su metodología de análisis, excesivamente dependiente de las fuentes literarias de la época y que bus$\mathrm{ca}$, en numerosas ocasiones, dar fuerza a sus argumentos más mediante la simple acumulación de citas que proporcionando al lector un sólido discurso probatorio ${ }^{24}$. Con todo, la peor acusación que se le realizó fue la de anacronismo, ya que mostró una tendencia manifiesta a otorgar a los jóvenes romanos del siglo i a. C. unas ambiciones y un modo de vida que correspondían a los de la juventud de los países más desarrollados durante la década de los años sesenta y setenta del siglo pasado ${ }^{25}$. Entre las críticas que podríamos realizar al trabajo de Kleijwegt destaca, sobre todo, la poca atención prestada a las fuentes literarias ${ }^{26}$, que tienden a ser silenciadas, sobre todo cuando contradicen las tesis que el autor quiere expresar. Así, se pasaron por alto tanto aquellos estudios que evidenciaban la prolijidad de los términos utilizados por los autores antiguos a la hora de hablar de la infancia y de la juventud como aquellos análisis que, desde la historia del arte, daban cumplida cuenta del interés y del grado de detalle de los artistas a la hora de expresar las edades de los individuos que representaban ${ }^{27}$.

En definitiva, la mayor parte de las críticas se centraron no tanto en los resultados de investigación obtenidos como en la metodología de análisis empleada, lo que a fin de cuentas no testimonia sino la imposibilidad de dominar todos los distintos tipos de fuentes (ninguno de los autores

magistraturas menores a desempeñar por parte de los jóvenes romanos como paso previo a su entrada en el Senado, afirmó que estos tendían a ocupar estos puestos tan tarde como podían, de cara a ser recordados por los ciudadanos en las futuras elecciones a cuestor o a tribuno de la plebe.

23. Para la misma opinión, vid. Harlow, Mary y Laurence, Ray: Growing Up and Growing Old..., op. cit., p. 65. En este sentido, incluso Marc Kleijwegt, un autor poco sospechoso de atribuir a la adolescencia y a la juventud una singularidad propia, ha llegado a afirmar que "the full adult status was only reached by marriage, i. e. the setting up of a separate household». Cf. Kleijwegt, Marc: Ancient Youth..., op. cit., p. 57. No está de más recordar que, a diferencia de los griegos de época clásica, que quedaban libres de la autoridad paterna a los dieciocho años, los romanos permanecían bajo la manus del padre hasta que este moría o tenía a bien emanciparlos.

24. Esta crítica ya fue lanzada, en su momento, por el propio Kleijwegt. Entre las críticas actuales, destaca la de Laes y Strubbe. Cf. Laes, Christian, y Strubbe, Johan: Youth in the Roman Empire..., op. cit., p. 47.

25. Ibid., pp. 145-146.

26. Ibid., p. 18.

27. Sobre este tema, vid., por ejemplo, Beaumont, Lesley A.: "The Changing Face of Childhood", en Neils, Jenifer, y OAKLEY, John, H. (eds.): Coming of Age in Ancient Greece. Images of Childhood from the Classical Past. New Haven, 2003, pp. 59-83. 
mencionados, por ejemplo, hacía un uso extensivo de la arqueología, la cual tiene mucho que decir al respecto, por ejemplo, de las condiciones de vida de estos colectivos de población). Ello explica que, en los últimos años, la práctica totalidad de las obras dedicadas al estudio de niños y jóvenes en la antigüedad tengan un carácter colectivo, ocupándose cada autor de desarrollar solamente un tema específico dentro de su especialidad. Con todo, en cierta manera, esta situación es de lamentar, pues, en medio de la maraña de casos de estudio particulares -entre los cuales se sitúa este texto-, lo cierto es que siguen haciendo falta obras generales, aunque sean parciales, incompletas e ideológicamente sesgadas.

Autores como Ville Vuolanto han tratado de establecer una clasificación dentro de los estudios de la infancia en la antigüedad ${ }^{28}$. Así, en un primer momento, los temas de interés pasaban por la educación y el estatus legal de niños y adolescentes; posteriormente, se realizaron estudios que, sin dejar de todo de lado los elementos anteriores, buscaban analizar los procesos de socialización (incluidos los sentimientos) de estos colecti$\operatorname{vos}^{29}$. Finalmente, hizo su aparición la agency, que actualmente domina el panorama de la investigación puntera sobre la infancia y la juventud en la antigüedad ${ }^{30}$. Algunos investigadores, incluso, han comenzado a dar una vuelta de tuerca más a esta noción de cara a expresar, de una manera más

28. En mi opinión, la clasificación que se ofrece a continuación es válida también para periodizar los estudios referidos a la adolescencia y la juventud en la antigüedad.

29. Véanse, por citar solo algunos ejemplos, Dixon, Suzanne: The Roman Mother. Routledge, 1992, y Harlow, Mary y Laurence, Ray: Growing up and Growing Old..., op. cit. (esp. pp. 13-15), trabajo este último de capital importancia en tanto en cuanto ha llamado la atención sobre las posibles diferencias en el desarrollo físico (y en menor medida psicológico) de los niños y jóvenes de ambos sexos en la antigüedad en relación a la de sus homólogos actuales de los países desarrollados. En su opinión, el completo desarrollo, tanto en hombres como en mujeres, podía tardar dos años más de lo que resulta habitual hoy en día, dato el cual resulta sumamente relevante, en tanto en cuanto podría significar que, en las sociedades antiguas, la edad biológica podía primar sobre otras consideraciones a la hora de limitar (o no) la capacidad de acción del individuo, siendo además un elemento importante de cara a la percepción social del mismo como joven o adulto. Ya otros autores anteriores, como Mark Golden, habían intuido algo parecido. Este último autor, en su monografía sobre la infancia griega, evidencia claros préstamos de Kagan. Vid. Kagan, Jerome: The Nature of the Child. New York, 1984 (sobre todo pp. 73-111, donde se afirma que no debemos necesariamente concebir el desarrollo de los niños y jóvenes como un continuum, pues el desarrollo mental de los individuos puede extenderse hasta los veinticinco años de edad).

30. Vid. Vuolanto, Ville: "Experience, Agency, and the Children in the Past. The Case of Roman Childhood", en Laes, Christian, y Vuolanto, Ville (eds.): Children and Everyday Life in the Roman and Late Antique World. London, 2017, pp. 11-24 (para la clasificación mencionada, vid. pp. 11-12). 
atinada, la capacidad de actuación ejercida por los grupos de población subalternos -entre los cuales podríamos incluir a los jóvenes-. Así, Henar Gallego, por ejemplo, en relación a las mujeres evergetas, acuñó el interesante concepto de "agencia autónoma", que busca singularizar un proceder que no se encuentra mediatizado por los intereses de otras personas, y a través del cual el elemento volitivo del individuo prevalece ${ }^{31}$. Tendremos la oportunidad de ver algunos casos de este tipo de agencia durante el último apartado del trabajo, aunque lamentablemente no podremos extendernos demasiado en ellos debido a las limitaciones de espacio impuestas.

Abandonando ya el plano meramente historiográfico, pasaremos ahora a ofrecer una panorámica del tratamiento que mereció la juventud a ojos de algunos de los autores de la antigüedad grecorromana más (re) conocidos.

\section{La JuVEntud en la antigüedad II. Perspectivas Generales}

Uno de nuestros más importantes puntos de partida pasa por la constatación de que, en las Vidas, no se aprecia en absoluto una diferenciación en el tratamiento de las juventudes griega y romana. Al contrario, como afirma un influyente autor, todos los elementos de esta colección

31. Gallego Franco, Henar: "Género y agencia en la arquitectura cívica romana promovida por mujeres en el norte de África", en Martínez López, Cándida, y Ubric Rabaneda, Purificación (eds.): Cartografías de género en las ciudades antiguas. Granada, 2017, pp. 133-157. Vuolanto, Ville: "Experience, Agency, and the Children...", op. cit., pp. 15-18, recoge en su texto los requisitos que debe tener la agencia. Entre los mismos, destaca que esta tiene que ir orientada o bien al futuro o bien al presente, y expresarse mediante actos que se realizan de cara a conseguir una diferencia que ocurre, o bien en las redes sociales de los individuos, o bien en las estructuras de poder en las cuales estos se encuentran inmersos. En definitiva, el concepto de agency nos sirve para subvertir aquellos primeros patrones historiográficos que trataban de reconstruir la vida de los llamados "colectivos subalternos". Mediante la misma, por ejemplo, podemos apreciar cómo los niños y los jóvenes no son, en absoluto, sujetos pasivos, sino que son agentes de su propia historia. Véase, por ejemplo, Mustakallio, Katariina, y Hanska, Jussi: "Children in Pre-modern Europe. Agents and/or Objects?", en Mustakallio, Katariina, y Hanska, Jussi (eds.): Agents and Objects. Children in Pre-Modern Europe. Roma, 2015, pp. 7-10. Para unas interesantes reflexiones sobre la agency y su aplicación al contexto de la esclavitud de tiempos romanos, cf. Alvar Nuño, Antón: Cadenas invisibles. Los usos de la magia entre los esclavos del Imperio romano. Besançon, 2017 (pp. 19 y ss.). Por mi parte, y respecto a la infancia, he tratado de demostrar la existencia, dentro de las Vidas, de algunos testimonios que hablan en favor de la agencia de este grupo de población. Vid. Méndez SANTiago, Borja: "Vulnerabilidad infantil en las Vidas Paralelas de Plutarco", en Rubiera Cancelas, Carla (ed.): Las edades vulnerables. Infancia y vejez en la Antigüedad. Gijón, 2018, pp. 87-110. 
de biografías tienden a analizarse a partir de un marco moral e ideológico de referencia común -típicamente griego- que es utilizado por Plutarco a lo largo de toda una extensísima obra de claros tintes didácticos y moralizantes $^{32}$.

No es este el lugar para detallar esta problemática, que lleva ocupando a los especialistas de Plutarco durante generaciones. Lo que nos interesa llevar a cabo en este apartado es contextualizar la (ambivalente) percepción que algunos relevantes autores griegos y romanos tenían, en la antigüedad, respecto a los miembros adolescentes y jóvenes de sus respectivas sociedades ${ }^{33}$. Solo después de ello, y ya en el último apartado del trabajo, aflorará la peculiar visión que Plutarco ofrece de los jóvenes en sus relatos biográficos. Esta, como veremos, es estrechamente dependiente de toda una tradición literaria anterior de la que nuestro autor, evidentemente, no se puede desprender y que, de alguna manera, condiciona su particular visión de la juventud.

Autores muy cercanos temporalmente a Plutarco, como Séneca, se mostraron muy preocupados respecto a la juventud romana ${ }^{34}$. Así, este último, según las palabras insertas en un interesante trabajo de investigación, entendía que su fogosidad juvenil les hacía propensos a desperdiciar su tiempo «en una serie de actividades que parecían no conducir a ninguna parte ${ }^{35}$. Ahora bien, los griegos y romanos de la antigüedad eran perfectamente conocedores de que este tipo de comportamientos, al menos en la mayor parte de los casos, podían constituir tan solo un paréntesis temporal 262.

32. Vid. Duff, Timothy: Plutarch's Lives. Exploring Virtue and Vice. Oxford, 1999, p.

33. De manera muy breve para lo que el argumento requeriría, baste afirmar que en este trabajo se defiende que la entrada plena en la edad adulta del joven -en el caso de las élites griega y romana- se producía de manera escalonada en un proceso bastante largo que culminaba aproximadamente cuando, a los treinta años de edad, estos recibían el derecho de ser elegibles a las magistraturas ciudadanas (en el caso griego) o al Senado (en el caso romano).

34. Ya en el siglo II a. C., autores como Polibio (31, 25, 4-5) describieron a los jóvenes romanos como disolutos. Algunos de ellos, afirma "se dedicaban a la pederastia, otros frecuentaban los prostíbulos y muchos acudían a espectáculos musicales y a banquetes, con

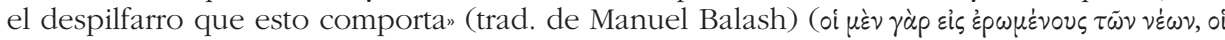

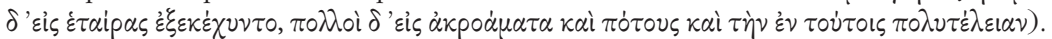

35. Cf. Bancalari Molina, Alejandro: "La problemática de la juventud en la sociedad romana: propuesta de enfoques para su estudio", Florentina Iliberritana, 9, 1998, pp. 41-68 (para la cita, vid. p. 66). Véase, además, Séneca, Ep. 95, 24-29, donde el filósofo y preceptor de Nerón se lamenta de los vicios en los que se encontraba inmersa la juventud (y la sociedad en general) de su tiempo, sobre todo en comparación con los tiempos pasados. Otras fuentes contemporáneas, como el poeta Persio $(4,39)$, también denuncian la existencia en Roma de una juventud ociosa y viciosa. 
en la vida de los jóvenes varones, antes de que estos se convirtieran en ciudadanos respetables y férreos defensores de las tradiciones patrias ${ }^{36}$. Así, podemos detectar que, al menos para algunos de los autores de esta época, los errores de juventud eran un rasgo característico de esta etapa vital, siendo hasta cierto punto comprensibles. Como demuestra un conocido pasaje del Pro Caelio de Cicerón:

Condescendamos un poco con la edad; tengan los jóvenes una mayor libertad; no cerremos todas las puertas al placer. No lleve siempre las de ganar la severa y rígida razón. Triunfen alguna vez la pasión y el placer sobre la razón; con tal de que en esto se guarde aquella justa medida [...] mas cuando, al final, hayan cedido a los placeres, dando algún tiempo a las diversiones propias de la edad y a esas frívolas pasiones de la adolescencia, vuélvanse algún día al cuidado de los negocios domésticos, de los forenses y de los públicos de modo que parezca que esas diversiones que antes no habían llegado a comprender bien, las han dejado ya por pura saciedad y las han despreciado a fuerza de vivirlas ${ }^{37}$.

Cicerón, Cael., $42^{38}$ (trad. de Jesús Aspa).

36. Eyben, Emil: "Fathers and Sons", en Rawson, Beryl (ed.): Marriage, Divorce and Children in Ancient Rome. Oxford, 1991, pp. 114-143 (esp. pp. 126-128), donde se aportan algunas referencias más a autores clásicos que se muestran comprensivos con estos "deslices" de la juventud.

37. detur aliquid aetati; sit adulescentia liberior; non omnia voluptatibus denegentur, non semper superet vera illa et derecta ratio; vincat aliquando cupiditas voluptasque rationem, dum modo illa in hoc genere praescriptio moderatioque teneatur [...].postremo, cum paruerit voluptatibus, dederit aliquid temporis ad ludum aetatis atque ad inanes hasce adulescentiae cupiditates, revocet se aliquando ad curam rei domesticae, rei forensis reique publicae, ut ea, quae ratione antea non perspexerat, satietate abiecisse, experiendo contempsisse videatur.

38. Para un interesante estudio que nos muestra a un Cicerón que dulcifica aparentemente sus creencias personales -mucho más rigoristas en otras obras como De Officiis- en relación a la juventud para lograr la absolución de su cliente, vid. Guerrero Contreras, Carmen: "La juventud romana en el "Pro Caelio" de Cicerón", Estudios Clásicos, 42, 118, 2000, 27-50. Previamente, en Cael. 28, Cicerón se había preocupado de destacar (sin citar ejemplos) que había habido individuos que "aun después de haber sumergido toda su juventud en el placer, han entrado en el buen camino, llegando a ser personas serias y hasta ilustres" (trad. Jesús Aspa) (sed qui totam adulescentiam voluptatibus dedissent, emersisse aliquando et se ad frugem bonam, ut dicitur, recepisse gravesque bomines atque illustres fuisse). Para la problemática relación entre juventud y virtus a través del Pro Caelio de Cicerón, vid. también Mcdonnell, Myles: Roman Manliness. Virtus and the Roman Republic. Cambridge, 2006 (esp. pp. 171-172). No obstante, Cicerón, en varios pasajes, se muestra en su faceta de moralista. Vid., sobre todo, Att. 1, 14, 11 (61 a. C.), donde habla de los barbatuli iuvenes. 
Sin embargo, estos mismos autores eran plenamente conscientes de que el rasgo más inquietante de la juventud no lo constituía, ni mucho menos, su conocida propensión al goce y disfrute de la vida. Lo verdaderamente preocupante para los literatos residía en la facilidad con la que los jóvenes eran influenciados por otras personas. Para ilustrar este hecho, y a la vez no alejarnos mucho del ejemplo anterior, veamos la ambigua actitud que Cicerón demostraba ante la impresionabilidad de los jóvenes. Por un lado, no dudó a la hora de criticar el empleo que de ellos hacía Catilina (vid., por ejemplo, Cael. 6, 13; Catil. II, 4, 8, o Mur., 49, donde denuncia que este personaje procuraba ir siempre acompañado por su tropa de jóvenes" -stipatum choro iuventutis- (trad. de Jesús Aspa); vid., también, Plutarco, Cic. 10, 4) ${ }^{39}$. Pero, si hemos de creer a ciertas fuentes, él mismo también pareció haber hecho un uso extensivo de la juventud de cara a lograr sus objetivos políticos ${ }^{40}$. Esta instrumentalización de la juventud por parte de ciertos políticos constituye no solo un reconocimiento implícito de la fortaleza que se percibía en este grupo de población, sino también un recordatorio acerca de la necesidad de mantener un cierto control en relación al mismo, de manera que la convivencia en el seno de la sociedad no se viera corrompida por posibles fluctuaciones consideradas indeseables $^{41}$. Buena prueba de la pervivencia en el tiempo de algunas de estas

39. También Salustio, en varios de los pasajes de sus obras, comenta el fuerte vínculo existente entre Catilina (contraejemplo por excelencia) y algunos sectores de la juventud romana (vid., sobre todo, Cat. 14 y 20). Esta atracción por los jóvenes resulta constatable en algunas de las Vidas romanas de Plutarco, como ocurre en los casos de Sila, de quien nuestro biógrafo afirma que "quiso tener como colaboradores a todos los jóvenes que estaban con él" (Cras. 6, 3, trad. de Amanda Ledesma) o de Pompeyo (Cat. Mi. 14, 5), quien llevó a cabo una política de captación similar.

40. En las Vidas, son varios los pasajes en los cuales Cicerón se aprovecha de los jóvenes, bien para garantizar su propia seguridad personal (Cic. 14, 7-14, 8), bien para tratar de despertar un sentimiento de compasión entre sus conciudadanos, que le veían condenado al exilio (vid. Cras. 13, 5, donde se afirma que el hijo de este consiguió movilizar a nada menos que 20.000 jóvenes para que, en señal de duelo, se vistieran de luto por Cicerón). En otras ocasiones, su instrumentalización de los jóvenes buscará otros fines, como demostrar que, aun alejado de la política, todavía seguía ejerciendo un importante ascendiente social sobre los hijos de las familias más influyentes (Cic. 40,1) o que, tras la muerte de los últimos cesaricidas en Filipos, todavía tenía mucho que decir en las más altas esferas a través de su relación con Octaviano (Cic. 45, 1-45, 2, donde Plutarco afirma que "el joven ( $\mu \varepsilon ı \alpha \dot{x} \kappa ı v)$ ponía tanto empeño en ganárselo que incluso lo llamaba padre", según la traducción ofrecida por Carlos Alcalde). Fuera o no esto último cierto, Octaviano acabaría vendiéndolo a Marco Antonio (cf. Cic. 46.1-46.2) en las persecuciones inmediatamente posteriores al establecimiento del llamado "segundo triunvirato".

41. En las propias Vidas, existen casos que demuestran la suspicacia de los romanos más tradicionales ante la irrupción de ciertos personajes que, con su sola presencia, 
concepciones sobre la juventud la encontramos en una fuente tan lejana en el tiempo como es el Digesto ${ }^{42}$. De lo apenas dicho en referencia a la influenciabilidad y manejabilidad de los jóvenes se deriva una consecuencia clara: la necesidad de supervisarlos constantemente para evitar que los errores de la juventud persistan más allá del tiempo en que la sociedad los considera admisibles. En definitiva, podemos colegir que, en la base de buena parte de los testimonios recogidos hasta el momento, se encuentra un cierto temor hacia la incapacidad de los jóvenes para distinguir lo bueno de lo malo ${ }^{43}$. Muchas personas, aún hoy en día, seguirían respondiendo de una manera muy similar a si creen que sus hijos adolescentes están capacitados para "saber lo que les conviene" o no.

Sin embargo, los griegos y romanos de la antigüedad eran plenamente conscientes de que los jóvenes representaban el futuro. Este aserto, que podríamos decir tiene validez universal, se muestra de una manera especialmente clara en el caso de los homines novi latinos. A través de algunas de las cartas enviadas por Cicerón, somos testigos de cómo este no solo envió a Grecia a su hijo Marco para que continuara con sus estudios superiores, sino que incluso llegó a mantener un gran contacto con las personas encargadas de su formación, demostrando en todo momento

conseguían "soliviantar" a la juventud. En la Vida de Catón el Viejo, se demuestra que el peligro también podía venir del exterior ( vid. Cat. Ma. 22-23). Este pasaje tal vez pueda ponerse en relación con la prohibición del año 161 a. C. a los maestros y pedagogos griegos de actuar de otra cosa distinta que de preceptores no pagados en las casas de las élites. Para una interpretación del mismo, vid. Sciarrino, Enrica: "Schools, Teachers, and Patrons in Mid-Republican Rome", en Bloomer, Martin W. (ed.): A Companion to..., op. cit., pp. 226-239 (esp. p. 233).

42. Véase, solo a modo de ejemplo, lo que afirma Calístenes en Dig. 48, 19, 28, 3, donde hace notar que los jóvenes llevan a cabo frecuentemente comportamientos "rebeldes" (seditiose) y "turbulentos" (turbulente).

43. Vid. Wiedemann, Thomas: Adults and Children in the Roman Empire. London, 1989, p. 24. Por citar un caso claro dentro de las Vidas, en Publ. 4, 1 se afirma que los hijos del cónsul Bruto, aún unos muchachos, "se dejaron convencer" ( $\sigma v v \varepsilon \pi \varepsilon i \sigma \theta \eta)$ para participar en una conspiración que atentaba contra la naciente República. Bruto, tras descubrir que en el complot participaban sus hijos, les dio la oportunidad de defenderse y, como no quisieron hacerlo, los condenó a muerte. Este es uno de los mitos fundacionales que han sustentado la creencia historiográfica en la severidad de los padres romanos, los cuales llegaban a ostentar, como en este ejemplo, el ius vitae necisque sobre todos los miembros de su familia. Para una imagen que trata de romper con este estereotipo de la figura del paterfamilias, vid. MÉNDEZ SANTIAGO, Borja: "Padres e hijos en las Vidas Paralelas de Plutarco", en Cid López, Rosa María (ed.): Familias, edades y género en el Mediterráneo antiguo. De la protohistoria a la historia. Madrid, 2019 (en prensa). 
un elevado interés acerca de sus progresos curriculares $(\text { Att. } 6,1,12)^{44}$. Además, para que pudiera llevar una vida acorde con su rango, no dudó a la hora de proporcionarle a su hijo medios económicos suficientes para que no quedara en desventaja en relación a otros jóvenes romanos de la aristocracia que también se encontraban en Atenas aprendiendo filosofía y otras disciplinas que, como la retórica y la oratoria, les serían de gran utilidad cuando comenzaran a dar sus primeros pasos en política ${ }^{45}$. Y es que para Plutarco la educación y sus efectos en el individuo constituyen uno de los temas más importantes dentro de su producción ${ }^{46}$, pues a través de ella la parte irracional del alma podía ser controlada y llevada hacia el bien de la mano del componente racional presente en aquella ${ }^{47}$. Autores

44. En las mismas Vidas Paralelas (Cic. 24, 8) existe un pasaje en el cual Cicerón, que era el encargado de diseñar la formación tanto de su hijo como de su sobrino Quinto, des-

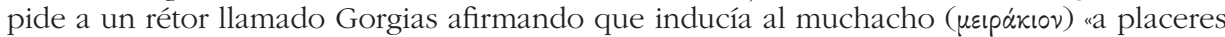

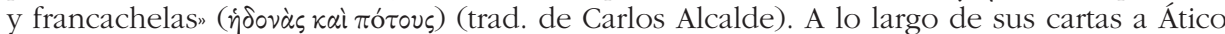
se comenta otro caso interesante, el del liberto Dionisio. Al parecer, tanto Marco hijo como Quinto se habían quejado del preceptor en alguna ocasión, lo que llevó a Cicerón, en un primer momento, a reafirmarlo en su puesto afirmando que "un hombre no puede llegar a ser más sabio ni más virtuoso, ni más afectuoso contigo y conmigo [se refiere a él mismo y a Ático]" (trad. de Miguel Rodríguez-Pantoja) (cf. Att. 6, 1, 12; sed bomo nec doctior nec sanctior fieri potest nec tui meique amantior). Sin embargo, en una carta fechada dos años después, Cicerón describe a este otrora reputado tutor como el "[maestro] más charlatán de todos y [...] menos apto para la enseñanza" (trad. de Miguel Rodríguez-Pantoja) (cf. Att. 8, 4, 1-2; hominem omnium loquacissimum et minime aptum ad docendum); dos días más tarde, y tras un breve impasse en el cual la reconciliación pareció posible, en otra nueva misiva a Ático, le comunica el despido de Dionisio en los siguientes términos: "lo dejé marchar a disgusto como maestro de los niños, pero sin pena como hombre desagradecido" (trad. de Miguel Rodríguez-Pantoja) (cf. Att. 8, 10; dimisi a me ut magistrum Ciceronum non lubenter, ut hominen ingratum non invitus). Para un reciente acercamiento a la educación de los miembros de la familia de Cicerón, vid. TReggiari, Susan: "The Education of the Ciceros", en Bloomer, Martin W. (ed.): A Companion to..., op. cit., pp. 240-251.

45. Vid. Sрётн, Thomas: "Cicero, Tullia, and Marcus: Gender-specific Concerns for Family Tradition?", en Dasen, Véronique, y SрÄтH, Thomas (eds.): Children, Memory, and Family Identity..., op. cit., pp. 147-172.

46. Teodorsson, Sven-Tage: "The Education of Rulers...", op. cit., p. 347. Vid., también, Xenophontos, Sofia: "Plutarch", en Bloomer, Martin W. (ed.): A Companion to..., op. cit., pp. 240-251 y, de una manera más general, Xenophontos, Sofía: Ethical Education in Plutarch. Moralising Agents and Contexts. Boston/Berlin, 2016.

47. Vid. Duff, Timothy: Plutarch's Lives... op. cit. (esp. pp. 72-75). Este autor afirma que, mientras "a person's nature is what he is born with; a person's character is related to his nature, but is affected, for better or worse, by the kind of life he or she habitually leads, and by the extent to which reason acts upon it" (p. 74). LaEs, Christian, y Strubbe, Johan: Youth in the Roman Empire. op. cit., p. 23, afirman que, aunque en la antigüedad se creía que el núcleo de la personalidad se encontraba fijado ya desde la infancia, era no obstante posible cambiarlo mediante el esfuerzo. Autores como Beneker han demostrado 
como Velázquez han llegado a afirmar que "es posible que ningún otro griego después de Platón haya concedido a la formación del hombre una importancia tal como Plutarco" ${ }^{48}$, aspecto que en mi opinión se encuentra más que probado por las relevantes monografías que se han publicado sobre el tema durante los últimos años ${ }^{49}$.

Para no extender demasiado la longitud de este epígrafe, y para dar algo de realce al pensamiento griego sobre la adolescencia y la juventud -del que Plutarco es heredero, pero sobre el que se ha investigado menos $-^{50}$, he considerado necesario terminar este epígrafe incluyendo un largo texto de la Retórica de Aristóteles, sin duda uno de los pasajes de referencia para entender la concepción de la adolescencia y la juventud que tenían la mayor parte de los autores antiguos, y que nos muestra a la perfección la ambivalencia característica de estos colectivos de población, situados a medio camino entre una infancia tildada de irracional y la gravitas que Cicerón consideraba la característica definitoria del hombre adulto:

Por su talante, pues, los jóvenes ( $\left(\mathcal{\varepsilon}_{\mathrm{o}} \mathrm{l}\right)$ son propensos a los deseos

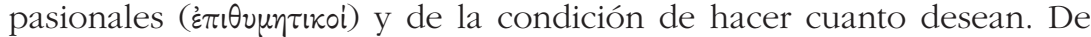
entre los deseos que se refieren al cuerpo son, sobre todo, dóciles a los placeres del amor (äko

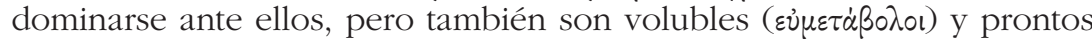

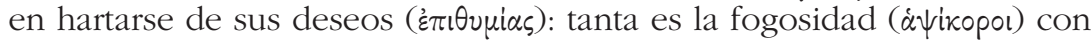
que desean como la rapidez $\left(\tau \alpha \chi^{\dot{\varepsilon}} \omega_{\varsigma}\right)$ con que se les pasa (pues sus afanes son agudos (

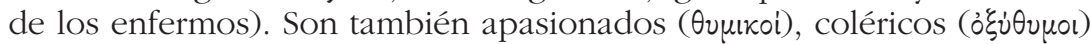

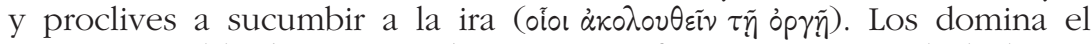

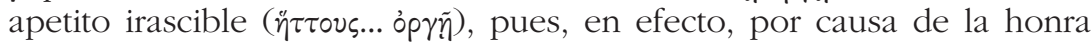

que, aunque la filosofía de Plutarco bebe más de Platón que de Aristóteles, en lo relativo a las "particiones del alma" se muestra mucho más cercano a la concepción dualista de este último que a la tripartita del primero. Cf. BeneKer, Jeffrey: The Passionate Statesman. Eros and Politics in Plutarch's Lives. Oxford, 2012 (esp. pp. 7-17, donde cita la bibliografía más relevante sobre el tema, y donde se recogen también las referencias necesarias para enmarcar filosóficamente el pensamiento de Plutarco en torno a esta problemática).

48. VelázQuez Fernández, Ana Esther: «Presencia y ausencia del educador en las Vidas de Plutarco", en Pérez Jiménez, Aurelio, y Casadesús Bordoy, Francesc (eds.): Estudios sobre Plutarco: misticismo y religiones mistéricas en la obra de Plutarco: actas del VII simposio español sobre Plutarco (Palma de Mallorca, 2-4 de noviembre de 2000). Madrid, 2001, pp. 441-450 (para la cita, vid. p. 441).

49. Entre ellas cabe destacar, por su importancia y por el hondo conocimiento de la obra de Plutarco que demuestra, Xenophontos, Sofía: Ethical Education in Plutarch..., op. cit.

50. Una notable excepción, que incide además en todo el recorrido vital de los individuos, es Iriarte, Ana, y De NAZARÉ Ferreira, Luísa (coords.): Idades e género na literatura e na arte da Grécia antiga. Coimbra, 2015. 
( $\phi i \lambda o \tau \mu \dot{\alpha} \alpha \nu)$, no soportan que se les desprecie, sino que se indignan

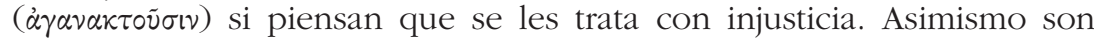

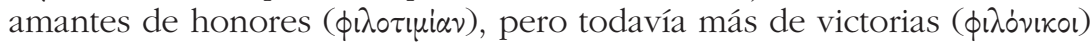
(porque el joven desea ser superior y la victoria constituye una cierta superioridad); y son más estas dos cosas que codiciosos ( $\phi 1 \lambda \circ \chi p \eta \dot{\mu} \mu \tau \circ \mathrm{l})$, si bien no son codiciosos porque no tienen experiencia de la privación

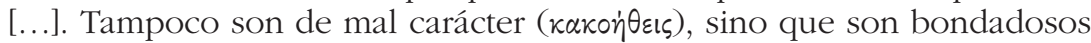

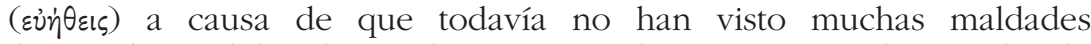

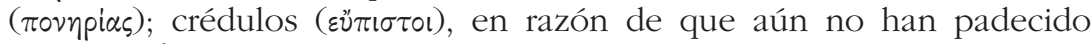
engaño ( $\dot{\xi} \xi \eta \pi \alpha \tau \tilde{\eta} \sigma \theta \alpha \iota)$ muchas veces; y optimistas ( $\varepsilon \dot{v} \dot{\varepsilon} \lambda \pi \imath \delta \varepsilon \varsigma)$ porque, lo mismo que los borrachos, así también los jóvenes son calientes por naturaleza ( $\delta \dot{\alpha} \dot{\theta} \varepsilon p \mu o$... $\dot{\tau} \pi \dot{o} \tau \tilde{\eta} s \phi \dot{v} \sigma \varepsilon \omega \varsigma)$, además de porque no han sufrido muchas decepciones. La mayoría de las veces viven llenos de esperanza ( $\dot{\varepsilon} \lambda \pi i \delta$ ), ya que la esperanza atañe al futuro, mientras que el recuerdo

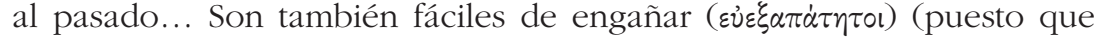
fácilmente se llenan de esperanzas), tienen el ánimo más valeroso

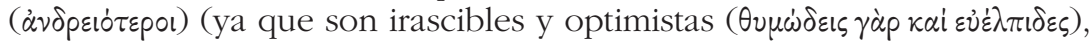
de modo que lo uno les hace no tener miedo ( $\phi \circ \beta \varepsilon i \tilde{\sigma} \theta \alpha$ ) y lo otro ser confiados ( $\theta$ appeiv), pues nada teme cuando tiene ira y el esperar un bien es causa de confianza), son también vergonzosos ( ai $\sigma \chi \nu \nu \tau \eta \lambda$ oi) [...] y son magnánimos ( $\mu \varepsilon \gamma \alpha \lambda o ́ \psi v \chi o ı)$ (ya que todavía no han sido heridos por la vida $\left(\tau \varepsilon \tau \alpha \pi \varepsilon i \nu \omega \nu \tau \alpha_{l}\right)$, antes bien carecen de experiencia de las cosas a que ella te fuerza...).

Aristóteles, Ret. 1389a3-1389a3351 (trad. de Quintín Racionero).

Tendremos la oportunidad de ver algunas de estas cualidades en el próximo apartado, en el cual los jóvenes aparecerán por fin en acción, mostrando cómo Plutarco era perfectamente consciente de buena parte de los postulados que hemos ido enunciando con anterioridad en este trabajo.

\section{Los Jóvenes en las Vidas Paralelas}

Han sido numerosos los autores que han afirmado que, en la época en que Plutarco escribió, hubo una especie de "cambio de mentalidad"

51. En mi opinión, resulta sumamente significativo que, justo a continuación de los jóvenes, Aristóteles comience a hablar de la vejez en términos completamente opuestos. En el próximo apartado tendremos la oportunidad de ver varios ejemplos de una construcción muy similar en las Vidas de Plutarco. 
respecto a los niños ${ }^{52}$, los jóvenes y la familia ${ }^{53}$. Plutarco se mostraría así no como un intelectual alejado de la sociedad en que vivía, sino como un miembro activo de la misma, algo que demostró, al igual que en sus escritos, en su vida personal, actuando como embajador en numerosas ocasiones $^{54}$. Sin embargo, y aunque Plutarco sea un hombre imbuido de la mentalidad de su tiempo, lo cierto es que, a lo largo de las páginas de sus obras, se muestra deudor de una gran tradición filosófica que hunde sus raíces en el platonismo, lo cual queda perfectamente reflejado en las valoraciones que emite a lo largo de toda su producción.

A diferencia de Eyben, yo no pretendo, en este epígrafe, ofrecer una visión general de la juventud en Plutarco, pues un estudio de tal magnitud bien merecería una monografía específica. Aunque Plutarco aborda en su obra realidades tan lejanas -cronológica y espacialmente-como la Atenas de Teseo y la Roma de Galba y Otón, lo cierto es que, de manera nada sospechosa, el tratamiento general que se hace de la juventud en las Vidas Paralelas resulta bastante homogéneo, al basarse en unos estereotipos de larguísima duración de los que hemos tratado de dar cuenta, de la mejor manera posible, en el epígrafe anterior del presente trabajo.

Pasamos, a continuación, a comentar solo los que en mi opinión son algunos de los rasgos más importantes asociados a los jóvenes en las Vidas de Plutarco.

Dos de las características asociadas a la juventud son su fortaleza y su valor, cualidades que se pueden demostrar de distintas maneras. Así, en Tem. 10, 8 se destaca la fortaleza psicológica de los hijos -cuya edad no se especifica- de los atenienses pues, a la hora de tener que abandonar su ciudad, no se dejan «dominar por los lamentos, los llantos y abrazos de sus padres, ${ }^{55}$. En otras ocasiones, una naturaleza excepcional se demuestra

52. Véase, por ejemplo, SoAres, Carmen: "Parent-Child Affection and Social Relationships in Plutarch: Common Elements in Consolation ad uxorem and Vitae", en Nikolaidis, Anastasios, G. (ed.): The Unity of Plutarch's Work..., op. cit., p. 720.

53. La mayor parte de los autores defienden que este cambio es detectable ya en el siglo I a. C., aunque los primeros indicios del "cambio" podemos encontrarlos, al menos en el mundo romano, ya en los siglos III y II a. C., gracias a ciertos pasajes insertos en las comedias de Plauto (por ejemplo, en Bac. 1076-1084, donde un padre se muestra hasta cierto punto comprensivo con los vicios de su hijo, a quien dio dinero para que pudiera satisfacer sus deseos).

54. Pese al tiempo ya transcurrido desde su publicación, vid. Russell, Donald A.: Plutarch. London, 2001 [1. ${ }^{\text {a }}$ ed., 1972], que continúa siendo uno de los mejores acercamientos a la vida y obra de Plutarco desde una perspectiva general.

55. Justo a continuación, y a modo de contraste dramático, Plutarco compara el valor de los jóvenes atenienses con el desamparo y la lástima que inspiraban los ancianos que se quedaban en esta misma ciudad, próxima a ser destruida por los persas (Tem. 10, 9); 
mediante otro tipo de actos, como la tranquilidad con la que el joven Pompeyo manejó un complot contra su padre del que se le puso sobre aviso (vid. Pomp. 3) $)^{56}$, o mediante un hecho tan insólito -no se encuentra otro caso tan claro en las Vidas - como que sea el individuo más joven (en este caso Foción) el que, aun aprendiendo de la experiencia de su superior -el general Cabrias-, no dude a la hora de corregir "la naturaleza de aquel,

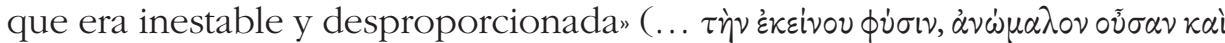

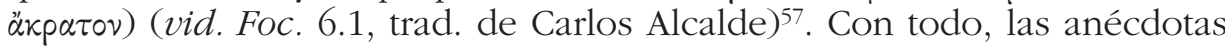

para unos ancianos que también deciden quedarse en la ciudad, pero cuya actitud es muy diferente, vid. Cam. 21, 4-22, 8, donde se destaca la impasibilidad y el arrojo de los ancianos romanos frente a los invasores galos. Esta escena constituye un interesante punto de comparación entre dos Vidas que, recordemos, constituyen una pareja en el corpus plutarqueo. Autores como Duff han criticado duramente la tendencia de algunos editores modernos a presentar las distintas Vidas de manera aislada, esto es, disociadas de su pareja, pues ello nos limita a la hora de comprender las motivaciones que tuvo Plutarco a la hora de contraponer a ambos personajes. Vid. Duff, Timothy: Plutarch's Lives..., op. cit., p. 250, donde también se afirma que, en la práctica totalidad de las ocasiones, "the first Life sets a pattern which is then exploited and varied in the second", asi como Pelding, Christopher: "Synkrisis in Plutarch's Lives", en Brenk, Frederick, y Gallo, Italo (eds.): Miscellanea Plutarchea (Atti del I convegno di studi su Plutarco, Roma, 23 novembre 1985). Ferrara, 1986, pp. 83-96.

56. Para otra interesante alusión a esta capacidad de Pompeyo para hacer frente a situaciones complicadas de la mejor manera posible, vid. Sert. 27, 4-27, 5, donde este decide enterrar el pasado quemando unas cartas incriminatorias que, de haber salido a la luz (pues en ellas muchos personajes relevantes de Roma le prometían su apoyo a Sertorio en caso de que este lograra imponerse en la batalla), hubieran probablemente desembocado en un baño de sangre. Las palabras con las que Plutarco concluye el relato del episodio resultan muy significativas: "Pompeyo..., realizando una acción no propia de una mente

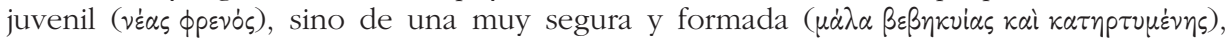
libró a Roma de grandes miedos y revueltas" (trad. de Juan Manuel Guzmán). Lo interesante, en este pasaje, en relación a lo que estudiamos aquí, es que se trata de un caso más de indeterminación etaria, ya que, por aquel entonces, Pompeyo tendría unos 34 años de edad. Para una cita semejante, en la que se afirma que el valor y el celo demostrados por Agis -bastante más joven que Pompeyo- durante su reunión con Arato "no tenían nada de

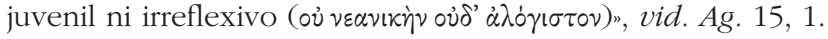

57. Adviértase que, en esta ocasión, se produce una clara inversión de roles. Así, si lo habitual en las Vidas resulta que el joven sea impulsivo y el hombre maduro más templado, aquí ocurre lo contrario, siendo esta una de las maneras preferidas de Plutarco para anticiparnos el futuro carácter que tendrá su biografiado una vez se encargue, como adulto, de sus funciones en la polis. En la Vida de Sila también encontramos otro ejemplo que testimonia la presencia, al menos en algunos jóvenes, de otra clase de valor. En Sil. 31, 1 se cita que tan solo un joven, llamado Cayo Metelo, "se atrevió a preguntar a Sila en el senado si iba a poner fin a sus desgracias y podían esperar que cesaran [se está refiriendo, en ambos casos, a las proscripciones], (trad. de Jorge Cano). Otro ejemplo resulta también ilustrativo de este tipo de valentía. En Luc. 21, 6 se nos muestra al joven Apio Claudio (más conocido como Clodio) entrevistándose como embajador con Tígranes, el 
más comunes son las que inciden en la valentía mostrada por los jóvenes protagonistas de cada una de las Vidas durante sus primeras campañas militares $^{58}$.

Resulta comprensible que, junto a estas descripciones del valor personal, Plutarco suela incluir otras ideas que, al hilo de la narración, le sirven para presentar al lector otros de los rasgos esenciales que caracterizarán la vida de sus personajes durante su edad adulta. Veamos, a modo de ejemplo, parte del "retrato moral" que se hace del joven Lúculo en su correspondiente Vida:

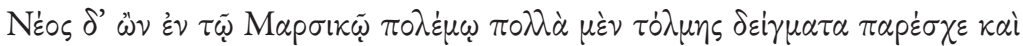

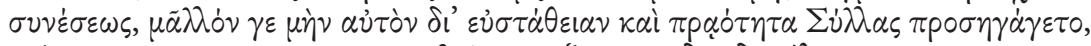

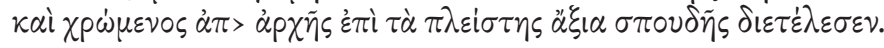

Aunque era solo un muchacho durante la guerra mársica, proporcionó sobradas pruebas de su valor y arrojo, pero más bien a causa de su firmeza y dulzura fue por lo que Sila lo tomó en su confianza y lo utilizó desde el principio hasta el último momento para que desempeñase puestos de gran responsabilidad.

\section{Luc. 2, 1 (trad. de David Hernández).}

Otro rasgo interesante que comparten algunos jóvenes tiene que ver con la liberalidad que demuestran en sus gastos. En la Vida de Antonio, de hecho, la prodigalidad se encuentra presente desde el principio de la biografía, cuando vemos que el padre de Antonio, aunque no tenía un gran

rey de Armenia, quien, aunque "trataba de escuchar[le] con rostro tranquilo y esbozando una sonrisa, no pudo ocultar a los presentes su desagrado por la franqueza ( $\pi$ app $\eta \sigma i \alpha)$ de aquel joven, pues hacía veinticinco años que no escuchaba un discurso con tanta libertad de palabra" (trad. de David Hernández). Volveremos sobre este pasaje más adelante.

58. Vid., por ejemplo, Pyrrh. 4, 4, donde se nos muestra a un jovencísimo Pirro dando pruebas de su valor en la batalla de Ipsos; Mar. 3, 2-3, 3, de quien se afirma que, en Numancia, destacó "de entre los demás jóvenes de su edad por su bravura ( $\alpha \dot{\nu} \delta \rho \varepsilon \dot{\alpha} \alpha$ ), asî como por el entusiasmo con que acogió las reformas que Escipión tuvo que introducir en su ejército, que se encontraba adocenado por el lujo y la molicie (trad. de Óscar Martínez)

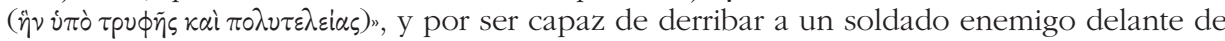
su general; Luc. 2, 1, quien proporcionó "sobradas pruebas de su valor y arrojo" ( $\tau \dot{\partial} \lambda \mu \eta \varsigma . .$.

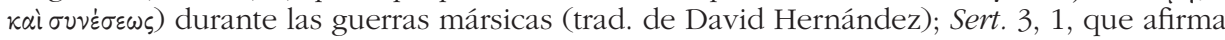
que el joven Sertorio -en una demostración de gran fortaleza- solo se retiró del combate contra los marsos cuando su cuerpo estaba cubierto de heridas, cruzando a nado, completamente armado, el Ródano; Ant. 3, 9, donde Antonio, bajo las órdenes de Gabinio, "siempre dio muestras de su gallardía y de una sagacidad propia de un general" (trad. de Juan Pablo Sánchez) o T(iberio) G(raco) 4, 5-4, 6, de quien se afirma que, estando en Libia bajo las órdenes de su cuñado Escipión Emiliano, "rápidamente... superó a todos los jóvenes

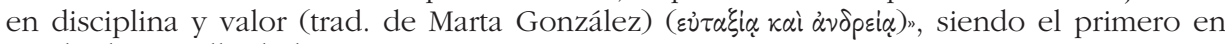
escalar la muralla de los enemigos. 
patrimonio, con tal de dar muestras de su largueza a uno de sus conocidos, le ofreció una tina de plata para que se la llevara como presente ${ }^{59}$. En un momento posterior de la narración, se nos muestra a un joven Antonio que, acompañado de su amigo Curión, es iniciado en una vida de libertinaje, hasta el punto de que solo puede saldar sus deudas gracias a que este último se las paga (vid. Ant. 2, 4-2, 5). Posteriormente, y para hacer de la cuestión de la excesiva liberalidad una especie de "herencia familiar", Plutarco menciona que Antilo -hijo de Antonio y de Fulvia-, como pago a un comentario ingenioso mientras estaba cenando, ofreció a su emisor "una mesa repleta de muchos y muy variados tipos de vasos" (trad. de Juan Pablo Sánchez), al igual que había hecho su abuelo al principio de la Vida (para la escena completa, vid. $28,7-28,12)^{60}$. Sin embargo, aunque

59. Resulta sumamente interesante constatar que, a la hora de realizar este regalo, el padre de Marco Antonio tuviera que engañar tanto a uno de los esclavos de la casa como a su mujer, que "le impedía mostrarse dadivoso". Esta mención no solo no es gratuita, sino que se relaciona estrechamente con la noticia (transmitida en Ant. 10, 5-10, 6) de que Antonio le debió (ó $\phi \varepsilon i \lambda \varepsilon v v)$ a su esposa Fulvia el haberle enseñado una sumisión que, posteriormente, le serviría a Cleopatra para tomar posesión de él, ya que, cuando el romano llegó hasta ella, ya "estaba amansado y medianamente instruido en obedecer a

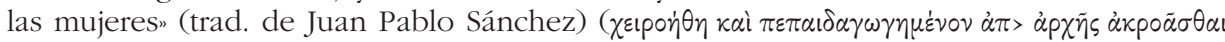

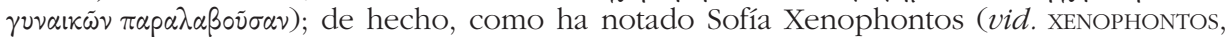
Sofía: Ethical Education in Plutarch... op. cit., p. 123), el lenguaje alusivo a la educación también se encuentra presente en Ant. 29, 1, cuando se afirma de la reina egipcia que

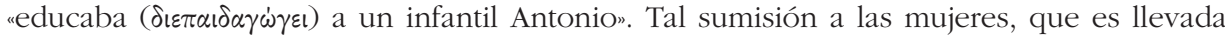
a su máxima expresión en los capítulos finales de la biografía, motivará que Antonio sea calificado, de una manera inusual dentro de las Vidas Paralelas (Ant. 62, 1), como "an

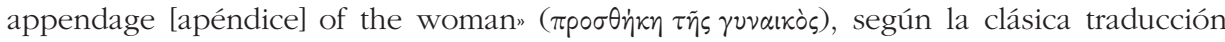
de Bernadotte Perrin para la Loeb Classical Library, que me parece, en este aspecto, más acertada que la ofrecida en castellano por Juan Pablo Sánchez para la editorial Gredos. Para un Antonio que hubo de "compartir la masculinidad de su casa con otra entidad [Fulvia]", cf. Antela-Bernárdez, Borja: "Sumisas, suicidas y dominatrices. Modelos femeninos del final de la República romana", en Antela-Bernárdez, Borja; Zaragozà Serrano, Claudia, y Guimerà MarTínez, Ariadna. (eds.): Placer y dolor: las mujeres en la Antigüedad. Madrid, 2017, pp. 109-136 (esp. p. 125). Creo que la afirmación aquí recogida también podría emplearse para hacer alusión al control de Antonio por Cleopatra al que hemos hecho alusión anteriormente.

60. Podemos constatar en Plutarco la creencia de que ciertos rasgos del carácter pueden transmitirse de generación en generación. Por citar solo otro caso, también relativo a la herencia de un defecto del abuelo por parte del nieto (una propensión a la bebida), vid. Cim. 4, 4. Sobre este interesante tema, véase, por ejemplo, RosKam, Geert: "Educating the Young... over Wine? Plutarch, Calvenus Taurus, and Favorinus as Convivial Teachers", en Ribeiro Ferreira, José, Leão, Delfim, Troster, Manuel y Barata Dias, Paula (eds.): Symposion and Philanthropia in Plutarch. Coimbra, 2009, pp. 369-383. Plutarco, aunque generalmente indulgente en relación al gusto por la bebida que demuestran algunos de sus personajes (vid. Cat. Ma. 6, 1-6, 4), no duda a la hora de criticar a quienes o 
es verdad que, en la línea del texto de Aristóteles citado más arriba, los jóvenes rara vez muestran en las Vidas un excesivo interés por las cuestiones materiales ${ }^{61}$, lo cierto es que no son inmunes a la riqueza, llegando a rebelarse en ciertas circunstancias extremas en las que se puede inferir una especie de conflicto intergeneracional. Vemos esto, por ejemplo, en la Vida de Pericles, donde se nos muestra tanto a sus hijos "mayores de edad"

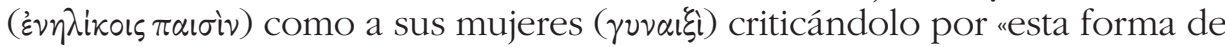
gastar al día y ajustado al céntimo, donde no se deslizaba nada superfluo, como es normal en una casa grande y de boyante situación" (vid. Per. 16, 5, trad. de Aurelio Pérez Jiménez) ${ }^{62}$.

Evidentemente, no todos los rasgos con los que se presenta a la juventud son positivos. Sin embargo, lo cierto es que actitudes similares pueden ser evaluadas por Plutarco de manera muy distinta, pues nuestro autor tiende a adaptar sus juicios morales en función de las exigencias del contexto específico del que se encuentra hablando. Así, si en el episodio comentado en Luc. 21, 6 (al que ya hemos hecho alusión en la nota 57) podemos rastrear la admiración de Plutarco por la libertad de palabra demostrada por el joven Clodio ante todo un monarca como Tígranes, también podemos interpretar el pasaje como un intento de demostrar la

bien cometen errores irreparables durante sus borracheras (vid. el caso de Clito, narrado en Alej. 50, 9-51, 11, escena que en mi opinión representa de alguna manera la realización efectiva de lo insinuado ya en el famoso enfrentamiento protagonizado por Filipo y Alejandro en los primeros capítulos de la Vida-vid. Alej. 9, 6-9, 11-) o se abandonan a ella y a otros excesos por completo (vid. Comp. Demetr.-Ant. 6, 1, donde Plutarco, com-

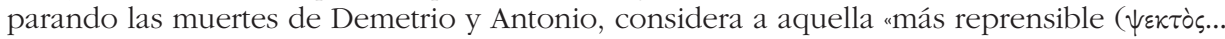
$\mu \tilde{\alpha} \lambda \lambda_{0}$ ), pues [Demetrio] permaneció como prisionero, cautivo y se dejó abandonar durante tres años hasta reventar de vino y comida, dejándose domesticar como los animales" (trad. de Juan Pablo Sánchez). Para una interesante medida disciplinaria de un padre en relación a su hijo, y que pasó por enviarle a Esparta para tratar de que dejara de ser alguien "bebedor e indisciplinado" ( Alcalde). Sin embargo, como Plutarco demuestra al final de la Vida (vid. Foc. 30, 2 y 38, $2-38,3)$, estas insólitas medidas no surtieron el efecto deseado, pues, aunque el joven, ya convertido en un hombre, llegó a realizar algunas buenas acciones, lo esencial de su naturaleza no cambió.

61. Para otro ejemplo, esta vez relativo a la liberalidad del joven Ciro, vid. Lis. 9, 1. También individuos como Cimón (Cim. 10, 1) y Pelópidas ( Pel, 3, 1) se caracterizaron por ser muy generosos con los que más lo necesitaban.

62. Autores como Saller son de la opinión de que los hijos adultos, tanto en Grecia como, sobre todo, en Roma, debían de tener una cierta cantidad de dinero cedida por sus padres y que podían administrar con cierta libertad. Vid. SAller, Richard P.: "Pietas, Obligation, and Authority in the Roman Family", en KneIssL, Peter, y Losemann, Volker (eds.): Alte Geschichte und Wissenschaftsgeschichte: Festchrift für Karl Christ zum 65. Darmstadt, 1988, pp. 393-410 (esp. p. 397). 
superioridad del sistema romano republicano en relación con la tiranía oriental $^{63}$. No obstante, y como decíamos más arriba, en ocasiones actitudes en apariencia similares son evaluadas desde una perspectiva diferente. Este es, por ejemplo, el caso de la conocida versión de Plutarco acerca de la (también osada) petición de Pompeyo a Sila de que le dejara celebrar un triunfo a pesar de que ni tenía la edad necesaria para ello ni era, por entonces, ni siquiera senador (vid. Pomp. 14, 1-14, 5). La crítica-que para ser sinceros no es ni mucho menos explícita, aunque creo que puede intuirse con facilidad- viene situada justo a continuación, cuando se nos muestra a un Pompeyo que, lejos de contentarse con este gran logro, y con la intención de irritar a sus rivales aún más, «intentó hacer la entrada [en Roma] montado sobre un carro tirado por cuatro elefantes" (Pomp. 14, 6; trad. de Salvador Bueno).

Ya hemos mencionado brevemente, en el apartado anterior, la propensión de los jóvenes a ser influenciados por los demás. Encontramos, dentro de las Vidas, numerosos ejemplos que, con mayor o menor grado de detalle, podríamos utilizar aquí. En Ages. 20, 8, el traductor de la editorial Gredos (Salvador Bueno) considera que Plutarco alude al control ejercido

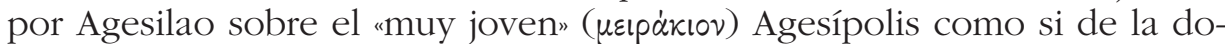
mesticación de un animal se tratara ${ }^{64}$. Cuando no eran demagogos los que

63. Tal interpretación de Plutarco, además, va en contra del juicio eminentemente negativo que se ofrece de Clodio en el resto de episodios en los que aparece (entre los que citamos, por ejemplo, Pomp. 46, 7-46, 8, en los que este personaje -por entonces tribuno de la plebe-aparece como jefe de los jóvenes, y donde se le califica como el más

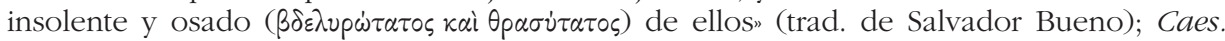
10, 1, donde se comenta el famoso episodio en el que Clodio invadió la casa del Pontifex Maximus durante la celebración de las fiestas de la Bona Dea, y Cic. 28, 1-28, 2, donde se le califica de "joven de edad pero atrevido $(\theta p \check{\alpha} \sigma \breve{\varsigma} \varsigma)$ y arrogante ( $\alpha v \theta \dot{\alpha} \delta \eta \varsigma)$ " (trad. de Carlos Alcalde)). En la cita de la Vida de César, se califica interesadamente a Clodio como imberbe" ( $\gamma \varepsilon v \varepsilon i \tilde{\omega} \nu)$; este término, con todo, está mayormente asociado en las Vidas a Pompeyo, sobre todo en escenas en las cuales Plutarco quiere recalcar su precocidad (Pomp. 14, 2 y 23, 2, y Sert. 18, 3). En lo que se refiere a las Vidas griegas, solo he atestiguado el uso de este vocablo en Sol. 9, 5. Este hecho, en mi opinión, debe ser interpretado no tanto como una demarcación exacta de la edad del personaje sobre el cual se está hablando como en la utilización, por parte de Plutarco, de una fuente común a la hora de redactar las Vidas romanas de finales de la República, que al parecer fueron escritas con un corto espacio de tiempo entre sí. Véase, a este respecto, Pelung, Christopher: "Plutarch's Method of Work in the Roman Lives", Journal of Hellenic Studies, 99, 1979, 74-96.

64. La traducción del verbo $\chi \varepsilon\llcorner p o n \theta \eta$ es objeto de polémica. Si Flacelière y Chambry optan por "apprivoiser", el de la editorial Gredos (Salvador Bueno), siguiéndolos, ha traducido el vocablo por "domesticar". Sin embargo, Bernardotte Perrin, en su edición para la Loeb Classical Library, ha optado por afirmar que el joven "was brought under the sway (bajo el control) of Agesilaus». Dado que no poseo un grado de conocimiento del griego 
soliviantaban a las masas, eran los filósofos los que podían ganarse con una gran facilidad a su auditorio ${ }^{65}$. En ocasiones, el vínculo creado entre un maestro y su pupilo será tan fuertemente percibido por los individuos que promoverá el surgimiento de distintos tipos de amor. Plutarco diferencia entre casos (saludables) como el de Sócrates y Alcibíades (vid. Alc. 4), de otros tipos de amor mucho menos ejemplares como el narrado en Dion 13, 6, donde se nos afirma que el joven Dionisio, tirano de Siracusa, llegó a amar a su mentor Platón "Con una pasión tiránica" (Dion 16, 2, trad. de Marta González) ${ }^{66}$.

Otros protagonistas de Plutarco, pese a haber dado pruebas muy tempranas de su capacidad para no ser influenciados por los demás, en determinadas circunstancias se comportan como el resto de los jóvenes. Así, en la Vida de Catón el Joven existen dos episodios en los cuales vemos cómo incluso uno de los máximos exponentes del puer senex llega a perder el tan ansiado control de sí mismo. Si la primera de estas anécdotas (Cat. Mi. $7,1-7,2)$ nos muestra a un Catón que, despechado por una promesa de matrimonio incumplida, se da a la composición de unos yambos sobre el hombre que le había arrebatado a su prometida para desahogar su cólera

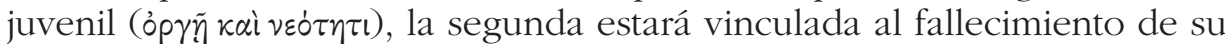
querido hermano (vid. Cat. Mi. 11, 3, donde se afirma que la reacción de Catón ante el deceso fue "más sentimental - $\varepsilon \mu \pi \alpha \theta \dot{\varepsilon} \sigma \tau \varepsilon p o v-$ que propia de un filósofo"; trad. de Carlos Alcalde). Resulta muy interesante que Plutarco, pese a ello, se muestre perfectamente condescendiente. Episodios como este prueban a la perfección que incluso los modelos de moralidad por excelencia tienen sus debilidades. Y es que, como afirmara en su momento Christopher Pelling, una de las claves del triunfo de las Vidas Paralelas

comparable al de ninguno de estos autores, me limito solamente aquí a resaltar la importancia de la correcta comprensión del matiz exacto que Plutarco nos quiso transmitir mediante su caracterización del personaje que estaba siendo manipulado.

65. Para la influencia de Esfero de Borístenes en Cleómenes, del que "quedó pren-

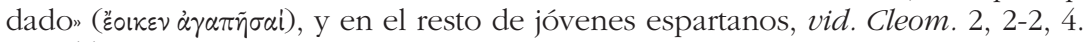

66. Cabe destacar que este individuo aparece en la Vida dedicada a su tío Dión como un joven que se encuentra a medio camino entre dos tipos de influencias: unas positivas (vid. Dion 16, a cargo de Platón) y otras negativas (vid., por ejemplo, Dion 7-8, donde se nos presenta a aquellos consejeros suyos que, rodeándole de lujos y proporcionándole toda clase de placeres, lo alejaron de cualquier posibilidad de cambio). Llama poderosamente la atención el hecho de que, en las Vidas, las relaciones maestro-pupilo que unen a Sócrates y a Platón con determinados jóvenes acaben en fracaso, pues estos individuos no consiguieron, respectivamente, volver ni a Alcibíades ni a Dionisio virtuosos. Del mismo modo, en la Vida de Alejandro Plutarco menciona que este, de querer a Aristóteles "tanto o más que a su padre", terminó distanciándose de él, pero no hasta el punto de querer hacerle daño (vid. Alej. 8.4). 
como biografías tuvo que ver, sin duda alguna, con su presentación de unos personajes que, al no ser nunca completamente buenos ni completamente malos, resultaban en el pasado (y resultan aún hoy en día) enormemente verosímiles a ojos de los lectores ${ }^{67}$.

Los jóvenes que aparecen en las Vidas se muestran, en algunas ocasiones, plenamente conscientes de la importancia social de su belleza. Esta puede estar, en primer lugar, relacionada con su buena presencia física. A este respecto debemos destacar sobre todo aquel pasaje inserto en las Vidas de César (Ces. 45, 2-45, 3) y Pompeyo (Pomp. 69, 3-69, 5) que nos muestra a los jóvenes componentes de la caballería de este último completamente aterrorizados ante la táctica de batalla planteada por los veteranos soldados de César, y que pasaba por apuntar con sus lanzas a sus rostros para desfigurarlos. Enfrentados a esta tesitura, los jóvenes, incapaces de soportarlo, fueron puestos en fuga con facilidad, decidiendo con su cobardía el destino de la República ${ }^{68}$. Pero la belleza, en segunda instancia, es también una cualidad que transciende lo meramente físico. Y, en las Vidas, lo cierto es que tenemos constancia de la importancia que los atuendos tenían para los jóvenes tanto en su vida civil como en el terreno militar. Respecto a la primera de ellas, en Cim. 10, 2 se afirma del protagonista del relato que siempre era seguido por "unos jóvenes acompañantes bien vestidos" (trad. de David Hernández) a los que encargaba, entre otras labores, repartir monedas entre los pobres más orgullosos. En relación al atuendo militar, resulta muy interesante la mención que se hace, en la Vida de Filopemén (Fil. 9, 6-9, 14), a las corazas doradas, los escudos

67. Vid. Peluing, Christopher: "Childhood and Personality in Greek Biography", en Peluing, Christopher. Plutarch and History: Eighteen Studies. Swansea, 2002, pp. 301-338 (esp. pp. 315-316).

68. Plutarco también recoge casos en los cuales los jóvenes se muestran orgullosos de las heridas recibidas en la batalla, algo especialmente perceptible en las Vidas romanas. Este es el caso, por ejemplo, de Catón el Censor, de quien se dice (Cat. Ma. 1, 7) que, "tenía, cuando era aún un muchacho, el cuerpo lleno de heridas recibidas de frente" (trad.

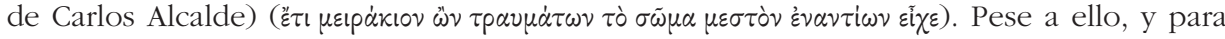
acabar con cualquier tipo de dudas acerca de que este hecho pudiera deberse a la temeridad del joven (y no a su virtud), Plutarco afirma justo a continuación que aquel se ofrecía a los combates "con mano agresiva, pero con pie firme y sólido, y orgulloso en el rostro" (Cat. Ma. 1, 8, trad. de Juan Manuel Guzmán). En la Vida de Emilio Paulo hay un pasaje que muestra a las claras dos modelos de masculinidad, uno digno de imitación y el otro digno de censura social. Mientras el primero corresponde al tribuno Galba, que es descrito como "un hombre sin heridas y con el cuerpo brillante por su lisura y su cultivo a la sombra" (Aem. 31, 7, trad. de Aurelio Pérez), el segundo corresponde a un antiguo cónsul llamado Marco Servilio que no dudó a la hora de mostrar al pueblo, desde la tribuna, no solo "un número increíble de heridas" recibidas en el pecho, sino su cuerpo completamente maltratado por años de campañas militares (vid. Aem. 31, 8-31, 10, trad. de Aurelio Pérez). 
ALGUNAS NOTAS HISTORIOGRÁFICAS

grandes, los frenos plateados, las túnicas de jinete bordadas y las clámides de los soldados, pues todos estos elementos contribuían a que los jóvenes combatientes aqueos se sometieran de mejor grado a los ejercicios y a las campañas militares, sirviendo el equipamiento a su vez tanto de elemento cohesionador del grupo como para diferenciar socialmente a los soldados de otros colectivos de población ${ }^{69}$.

Otro aspecto que guarda, en las Vidas, una estrecha relación con la juventud -sobre todo en el caso de las biografías que Plutarco dedica a personajes griegos-, es la homosexualidad masculina. En otro estudio he analizado la vulnerabilidad asociada a esos jóvenes que eran objeto de deseo (no correspondido) por parte de personajes más poderosos que ellos; en él quise sobre todo centrarme en el grado de agencia y autonomía demostrado por estos jovencitos, que en los tres casos recopilados eran adolescentes posiblemente situados entre los trece y los dieciséis años de edad $^{70}$. Por ello, a continuación, pasaré a centrarme en la respuesta emitida por algunos jóvenes contra sus antiguos amantes, concentrándome sobre todo en un par de casos específicos.

No es este el lugar para comentar la ambigua consideración que Plutarco parece mostrar ante la homosexualidad masculina ${ }^{71}$. Sin embargo, he

69. El orgullo a través de los atuendos bélicos es ya perceptible en Lic. 22, 1, donde se afirma que los jóvenes espartanos, aunque eran sometidos a una férrea instrucción, no tenían prohibido "presumir de sus cabellos ni del ornato de sus armas y mantos" (trad. de

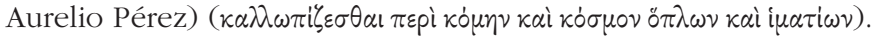

70. Vid. Méndez Santiago, Borja: "Vulnerabilidad infantil...", op. cit., pp 99-100. Los tres casos citados allí son los de Democles (Demetr. 24, 3-24, 5), Cleeneto (Demetr. 24, 6) y Damón (Cim. 1, 3 - 1, 5).

71. Para un acercamiento general a la homosexualidad griega, vid. Dover, Kenneth: Greek Homosexuality. Cambridge (Massachusetts), 1978, que sigue siendo el trabajo de referencia. Para una obra reciente de más amplia perspectiva, vid. HubBard, Thomas (ed.): A Companion to Greek and Roman Sexualities. Malden/Oxford/Chichester, 2013. Para un acercamiento a la (ambigua) postura de Plutarco acerca de la homosexualidad, vid. GARCíA LÓPEZ, José: "Relaciones personales en Moralia de Plutarco: familia, amistad y amor", en Pérez Jiménez, Aurelio, y Del Cerro Calderón, Gonzalo (eds.): Estudios sobre Plutarco: obra y tradición. Actas del I Symposion Español sobre Plutarco. Fuengirola, 1988. Málaga, 1990, pp. 105-122, donde se citan los pasajes más importantes dentro de los Moralia (751F, 752A, 768E -en contra- y 770C -donde se muestra más conciliador, pero solo en el caso de los "genuinos amantes"-); vid. también Tsouvala, Georgia: "Love and Marriage", en Beck, Mark (ed.): A Companion to Plutarch. Malden/Oxford/Chichester, 2012, pp. 191-201. Para la constatación de que los griegos concebían que estas relaciones no debían extenderse en el tiempo más allá de los límites considerados "adecuados", vid. Golden, Mark: Childhood in Classical Athens, op. cit., p. 60. Normalmente se ha tendido a minusvalorar el papel jugado por los individuos más jóvenes dentro de estas relaciones pederásticas. Sin embargo, véase Eger, Asa A.: "Age and Male Sexuality: "Queer Space" in the Roman Bath-House?", en Harlow, Mary y Laurence, Ray (eds.): Age and Ageing in the Roman Empire. Portsmouth, 
querido finalizar este acercamiento a la juventud tal y como aparece en las Vidas comentando algunos pasajes que considero esenciales. Plutarco, como en la mayoría de los aspectos que aborda en sus biografías, polariza este tipo de relaciones, que o bien están basadas en el respeto y el cariño mutuo más absoluto (vid. Sol. 1, 4-1, 5, que nos muestra a dos antiguos amantes, Solón y Pisístrato, que, guardando un buen recuerdo de la relación pasada, siguieron respetándose mutuamente durante toda su vida a pesar de que, cuando crecieron, pasaron a sostener una ideología política completamente diferente $)^{72}$, o bien son uniones pasajeras que se modifican en sus fundamentos una vez que el antiguo personaje subordinado alcanza una posición de poder. Para un posible ejemplo de esta última clase de relación, véase Ages. 7-8, y Lis. 23, 3-23, 6, donde se nos muestra a Agesilao reaccionando ante el poder y la autoridad exhibida por su antiguo

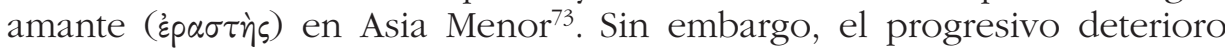
y extinción de una relación homoerótica por estos (u otros) motivos no suponía necesariamente el fin de este tipo de amores para el varón, sino que, simplemente, debía readaptar su papel en el mismo; así, el antiguo erómenos debía comenzar a actuar como erastés.

En las Vidas, además, existen varios casos que testimonian la resistencia de algunos individuos a las relaciones homoeróticas. Este rechazo puede demostrarse bien de manera enérgica (vid. Demetr. 24, -24, 5; Cim. 1, 3-1, 7; Mar. 14, 4-14, 8) o bien de otras formas menos extremas pero que

2007, pp. 131-151 (esp. p. 135, donde se comenta, a través del cap. 87 del Satiricón de Petronio, la actitud activa que podían ejercer los jóvenes dentro de las relaciones homosexuales).

72. Podemos encontrar un contrapunto -imperfecto- a esta actitud en Arist. 2, 4, un interesante pasaje en el que se afirma que el enamoramiento de Temístocles y Arístides por el mismo hombre, llamado Estesícleo, conllevó que «ambos no soportaran la pasión con medida, [de modo que] ni incluso al terminar la belleza del muchacho dejaron de lado su rivalidad" (trad. de Juan Manuel).

73. Vid. Lis. 22, 3 y Ages. 2, 1, donde se nos confirma que ambos personajes habían sido amantes cuando el rey de Esparta era joven. En Ages. 7, 4 Plutarco viene a afirmar que Agesilao, aun no siendo envidioso ante los éxitos y honores de los demás, no podía permitir un estado de cosas en que un subordinado llevara la voz cantante durante una importante campaña militar. Ahora bien, al final del relato de este desencuentro (Ages. 8, 6-8, 7) Plutarco parece reconocer que quizás las formas empleadas no fueron las más correctas, ya que ambos hombres eran partícipes de una misma "pasión" $(\pi \dot{\alpha} \theta \varepsilon l)$, en este caso destructiva. 
resultan igualmente efectivas ${ }^{74}$. Así, por ejemplo, del "bello" "75, "prudente" y "educado" hijo de Marcelo ( $\pi \alpha i$ s) se dice (vid. Marc. 2, 5-2, 8) que tuvo que soportar las proposiciones de Capitolino (por entonces edil), «un hombre

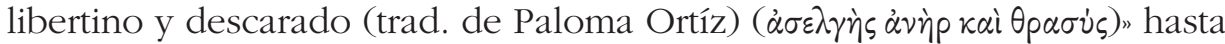
que el propio joven, tras contarle el problema a su padre, compareció en una vista judicial ante el Senado ${ }^{76}$. De Agesilao se nos cuenta que, enamorado por completo del joven hijo de Espitrídates, llamado Megabates (Ages. 11, 2), y atormentado por el deseo ( $\varepsilon_{p} \omega \varsigma$ ), hizo lo imposible por evitarlo, llegando a declarar a sus allegados que su lucha contra esta pasión era para él como un "combate" (i

\section{Conclusiones}

En este último apartado del trabajo hemos realizado un primer acercamiento a los jóvenes que aparecen en las Vidas Paralelas. Antes habíamos hecho alusión a una de las principales dificultades -la indeterminación de las fuentes clásicas a la hora de diferenciar, por medio de los términos empleados, las edades de los individuos- a la hora de estudiar estas franjas etarias, presentamos una polémica historiográfica de más de veinte años de duración que ha marcado profundamente los acercamientos a la temática que aquí se analiza y tratamos de exponer, siquiera brevemente, varios de los rasgos generales que algunos de los principales autores de la antigüedad -sobre todo Aristóteles y Cicerón- atribuían a los jóvenes y a los adolescentes en sus obras.

Han quedado en el tintero otras muchas cuestiones por tratar. Entre las mismas, quisiera destacar, por ejemplo, la contraposición -realizada muchas veces en el relato-, entre unos jóvenes que se muestran partidarios de soluciones drásticas y unos ancianos que se muestran mucho más

74. Adviértase que, en los tres casos mencionados aquí, la seducción incluye un claro componente de violencia, en el que el "abuso de superioridad" es patente (aunque, en el caso romano, hay un claro componente cultural en el rechazo a la homosexualidad en el ejército).

75. En las biografías de Plutarco encontramos solo una mención a alguien que, siendo mayor, es calificado de "bello". En Alc. 1, 4 se afirma del protagonista de la Vida que "Sobre su belleza física ( $\kappa \dot{\alpha} \lambda$ ovs) tal vez solo haya que decir que tanto de niño como de

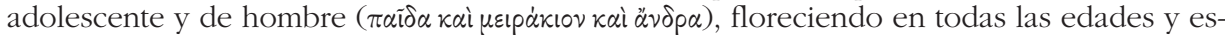

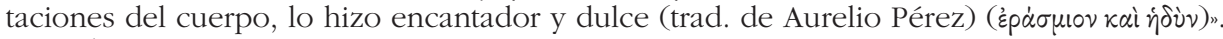

76. Llama la atención que, en el juicio, el elemento decisivo que hizo que Capitolino fuera declarado culpable fueron "su rubor y sus lágrimas y su vergüenza mezclada de cólera" (vid. Marc. 2, 5-2, 8, trad. de Paloma Ortíz). 
prudentes ${ }^{77}$. Tampoco hemos podido desarrollar en el espacio de este artículo la importancia que tiene, dentro de las biografías plutarqueas, un sentimiento de defensa del honor familiar que podríamos calificar grosso modo como la versión griega de la pietas romana, y que se muestra de manera evidente en aquellos casos en que los jóvenes, una vez llegados a la edad necesaria, se levantan bien contra los acusadores de sus padres (vid. Luc. 1, 2-1, 3, Cat. Ma. 15, 3) o bien se querellan contra unos tutores ineficientes que habían despilfarrado el dinero de la herencia con la cual el joven se habría de haber educado (Dem. 6, 1) ${ }^{78}$. En definitiva, que las Vidas Paralelas constituyen, tanto por la extensión cronológica y espacial que abarcan, como por su interés por el desarrollo vital de los personajes, un testimonio esencial para estudiar en su contexto las diferentes etapas vitales de los hombres (y, en menor medida, las mujeres) del pasado.

77. A este respecto, resulta muy interesante la caracterización opuesta que de los ancianos y los jóvenes realiza Plutarco en Sobre si el anciano debe intervenir en politica ( $A n$ seni sit gerenda respublica). En esta obra se afirma, por ejemplo, que "la juventud es algo hecho para obedecer, como la vejez para mandar" (Mor. 789D; trad. de Helena Rodríguez), trasluciéndose la idea de una complementariedad necesaria entre jóvenes y ancianos en los asuntos de gobierno (vid. Mor. 791B-C; 795A; 796B). Sin embargo, Plutarco advierte que el ansia de algunos ancianos por acaparar cargos y honores puede generar el rechazo de los políticos más jóvenes, ya que estos pueden sentirse sin oportunidades de actuar (cf. Mor. 793D). Para casos particulares, ya dentro de las Vidas, en los que podemos atisbar ciertas dosis de "conflicto intergeneracional", véanse, por ejemplo, Alej. 31, 10 - 31, 12, y

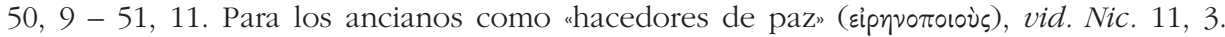
No obstante, y aunque ya hemos hablado de la influenciabilidad de los jóvenes, lo cierto es que, en determinadas circunstancias, también los ancianos se mostrarán partidarios de llevar a cabo arriesgadas campañas militares. Por ejemplo, tanto en Alc. 17, 4 como en Nic. 12, 1 se nos muestra a los viejos atenienses entusiasmados ante la perspectiva de llevar la guerra a Sicilia. Duff, Timothy: Plutarch's Lives..., op. cit., p. 120 ha defendido convincentemente que, cuando Plutarco nos presenta este tipo de conflictos, suele polarizar la opinión social diferenciando entre un sector más impulsivo -usualmente identificado con los más jóvenes o con los sectores menos educados de la población-, y otro más mesurado -a veces calificado como "los mejores" o "la parte útil de la sociedad"-. Sin duda alguna, como defiende el citado autor, Plutarco está tratando de guiar la mente del lector de cara a que se identifique con este último grupo.

78. A consecuencia de esta malversación de fondos el joven Demóstenes hubo de renunciar a recibir clases de Isócrates, debiendo conformarse con tener a Iseo como maestro de oratoria. La historia de la educación de este personaje es, frente a la de Cicerón (caracterizado como una especie de niño prodigio), una historia de superación personal, en la cual el protagonista se levanta (con tan solo un poco de ayuda) contra unos preceptores que le robaron su dinero (Dem. 4, 3), una madre que "no lo estimulaba para que se esforzara" (Dem. 4, 4), un cuerpo "flaco y enfermizo" (Dem. 4, 5) y un pueblo ateniense que, la primera vez que le escuchó hablar públicamente, le hizo el blanco de sus «burlas y abucheos" (Dem. 6, 4; traducciones de Juan Pablo Sánchez). 
A mi modo de ver, los estudios sobre adolescencia y juventud en la Grecia y Roma antiguas siguen siendo completamente necesarios para que nuestra disciplina continúe avanzando metodológicamente. En concreto, el estudio que hemos querido presentar aquí, basado exclusivamente en fuentes literarias, no constituye sino uno de los posibles acercamientos al tema, como lo pueden ser otros realizados desde una perspectiva sociológica, antropológica, arqueológica, artística, epigráfica o incluso psicológica. En este sentido, los estudiosos de la adolescencia y la juventud bien quisiéramos contar con obras colectivas recientes como la editada por Christian Laes y Ville Vuolanto ${ }^{79}$, o bien con fantásticas monografías como la recientemente publicada por Maureen Carroll, autora que, aunque explora la infancia en la antigüedad romana sobre todo a través de la que podríamos denominar "arqueología de la muerte", no duda a la hora de adentrarse en otros muchos aspectos de cara a presentarnos una imagen más omnicomprensiva de su temática de estudio ${ }^{80}$.

En definitiva, los nuevos estudios como estos no tratan tan solo de conocer mejor las condiciones de vida, las limitaciones o los privilegios de cada grupo de edad, sino también adentrarse, en la medida de lo posible, en las profundidades de una serie de construcciones culturales que, en definitiva, son las que determinan qué rasgos son (o no) aceptables en un grupo de población (o, en este caso, edad) específico. Así, si conseguimos mejorar nuestro conocimiento en relación a estos aspectos, se abre ante nuestros ojos un nuevo panorama historiográfico en el cual no solo podremos percibir el grado de agencia de los sujetos históricos que analizamos, sino que incluso alcanzaremos a ver sus sentimientos y motivaciones. Aquí, hemos centrado nuestra atención en presentar una nómina incompleta de algunos de los rasgos que Plutarco atribuye a la adolescencia y a la juventud (en concreto, nos hemos centrado en temas relacionados con su fortaleza, valentía, prodigalidad, influenciabilidad, belleza, y actitud ante la homosexualidad), dejando abierta, para más adelante, la posibilidad de realizar bien un estudio en profundidad sobre el tema, bien desarrollos específicos que, por ejemplo, comparen una o varias parejas de Vidas en relación a este foco de interés. Sin embargo, a la hora de llevar a cabo cualquier tipo de acercamiento literario a una realidad concreta, nunca debemos perder de vista -como he tratado de realizar aquí- que cada autor tiene toda una ideología y una tradición de tópicos detrás que

79. Laes, Christian, y Vuolanto, Ville (eds.): Children and Everyday Life..., op. cit.

80. Carroll, Maureen: Infancy and Earliest Childbood in the Roman World. "A Fragment of Time». Oxford, 2018. 
condiciona su narración de los hechos, y que, por tanto, ha de ser conocida antes de la realización de nuestros análisis subjetivos.

\section{BiBLIOGRAFÍA}

Alvar Nuño, Antón: Cadenas invisibles. Los usos de la magia entre los esclavos del Imperio romano. Besançon, 2017.

Antela-Bernárdez, Borja: "Sumisas, suicidas y dominatrices. Modelos femeninos del final de la República romana", en ANTELA-BERnárDEZ, Borja; Zaragoż̀ Serrano, Claudia, y Guimerà Martínez, Ariadna. (eds.). Placer y dolor: las mujeres en la Antigüedad. Madrid, 2017, pp. 109-136.

ARIÈs, Philippe: L'enfant et la vie familiale sous l'Ancien Régime. Paris, 1960 [hay trad. española, El niño y la vida familiar en el antiguo régimen. Barcelona, 1987].

Bancalari Molina, Alejandro: "La problemática de la juventud en la sociedad romana: propuesta de enfoques para su estudio". Florentina Iliberritana, 9 (1998), pp. 41-68.

Beaumont, Lesley A.: "The Changing Face of Childhood", en Neils, Jenifer, y OAKLey, John, H. (eds.). Coming of Age in Ancient Greece. Images of Childhood from the Classical Past. New Haven, 2003, pp. 59-83.

Beneker, Jeffrey: The Passionate Statesman. Eros and Politics in Plutarch's Lives. Oxford, 2012.

Bloomer, Martin W. (ed.): A Companion to Ancient Education. Malden/ Oxford/West Sussex, 2015, pp. 226-239.

BraDlEY, Keith: "Images of Childhood - The Evidence of Plutarch", en Pomeroy, Sarah. (ed.). Advice to the Bride and Groom and A Consolation to His Wife: English Translations, Commentary, Interpretative Essays, and Bibliography. Oxford, 1999, pp. 183-196.

CARroll, Maureen: Infancy and Earliest Childhood in the Roman World. "A Fragment of Time». Oxford, 2018.

Chankowski, Andrzej S.: L'éphébie hellénistique. Étude d'une institution civique dans les cités grecques des îles de la Mer Egée et de l'Asie Mineure. Paris, 2010.

Iriarte, Ana, y De NAZARÉ Ferreira, Luísa (coords.). Idades e género na literatura e na arte da Grécia antiga. Coimbra, 2015.

Dixon, Suzanne: The Roman Mother. London, 1992.

Dover, Kenneth: Greek Homosexuality. Cambridge (Massachusetts), 1978.

Duff, Timothy: Plutarch's Lives. Exploring Virtue and Vice. Oxford, 1999. 
Eger, Asa A.: "Age and Male Sexuality: "Queer Space" in the Roman BathHouse?", en Harlow, Mary y Laurence, Ray (eds.). Age and Ageing in the Roman Empire. Portsmouth, 2007, pp. 131-151.

EyBen, Emil: "Was the Roman "Youth" an Adult Socially?". L'Antiquité Classique, 50.1-2 (1981), 328-350.

Eyben, Emil: "Fathers and Sons", en Rawson, Beryl (ed.). Marriage, Divorce and Children in Ancient Rome. Oxford, 1991, pp. 114-143.

EyBEN, Emil: Restless Youth in Ancient Rome. London, 1993.

EYBen, Emil: "Children in Plutarch", en VAN Der STOCKT, Luc (ed.). Plutarchea Lovaniensia: a miscellany of Restless Youth in Ancient Rome. Essays on Plutarch. Leuven, 1996, pp. 79-112.

GaLlego Franco, Henar: "Género y agencia en la arquitectura cívica romana promovida por mujeres en el norte de África", en MARTínez López, Cándida, y UBric Rabaneda, Purificación (eds.). Cartografías de género en las ciudades antiguas. Granada, 2017, pp. 133-157.

GARcía López, José: "Relaciones personales en Moralia de Plutarco: familia, amistad y amor", en Pérez Jiménez, Aurelio, y Del Cerro Calderón, Gonzalo. (eds.). Estudios sobre Plutarco: obra y tradición. Actas del I Symposion Español sobre Plutarco. Fuengirola. 1988. Málaga, 1990, pp. 105-122.

Golden, Mark: Childhood in Classical Athens. Baltimore, 1990.

Guerrero Contreras, Carmen: "La juventud romana en el "Pro Caelio" de Cicerón". Estudios Clásicos, 42, 118 (2000), 27-50.

Harlow, Mary y Laurence, Ray: Growing Up and Growing Old in Ancient Rome. A Life Course Approach. London, 2002.

HubBard, Thomas (ed.): A Companion to Greek and Roman Sexualities. Malden/Oxford/Chichester, 2013.

Kagan, Jerome: The Nature of the Child. New York, 1984.

Kennell, Nigel M.: Ephebeia. A Register of Greek Cities with Citizen Training Systems in the Hellenistic and Roman Periods. Hildesheim, 2006.

Kleijwegt, Marc: Ancient Youth: The Ambiguity of Youth and the Absence of Adolescence in Greco-Roman Society. Amsterdam, 1991.

Laes, Christian, y Strubbe, Johan: Youth in the Roman Empire. The Young and the Restless Years?. Cambridge, 2014.

López Gregoris, Rosario: "La infancia en Roma", en Hernández Crespo, Rosa M. y Domínguez Monedero, Adolfo J. (eds.). Las edades del hombre. Las etapas de la vida entre griegos y romanos. Madrid, 2014, pp. 69-91.

Marrou, Henri: Histoire de l'éducation dans l'Antiquité. Paris, 1948 [hay trad. española, Historia de la educación en la antigüedad. Buenos Aires, 1970]. 
Mcdonnell, Myles: Roman Manliness. Virtus and the Roman Republic. Cambridge, 2006.

Mencacci, Francesca: "Modestia vs. Licentia. Séneca on Childhood and Status in the Roman Family", en Dasen, Véronique, y SPÄTH, Thomas (eds.). Children, Memory, and Family Identity in Roman Culture. Oxford, 2010, pp. 223-244.

Méndez Santiago, Borja: "Vulnerabilidad infantil en las Vidas Paralelas de Plutarco", en RUBIERA CANCElas, Carla (ed.), Edades vulnerables. Infancia y vejez en la antigüedad. Gijón, 2018, pp. 87-110.

Méndez Santiago, Borja: "Padres e hijos en las Vidas Paralelas de Plutarco", en CID López, Rosa María (ed.). Familias, edades y género en el Mediterráneo antiguo. De la protohistoria a la historia. Madrid, en prensa.

Mustakallio, Katariina, y Hanska, Jussi: "Children in Pre-modern Europe. Agents and/or Objects?", en Mustakallio, Katariina, y Hanska, Jussi (eds.). Agents and Objects. Children in Pre-Modern Europe. Roma, 2015, pp- 7-10.

NÉRAUdAU, Jean-Pierre: La jeunesse dans la littérature et les institutions de la Rome républicaine. Paris, 1979.

Nikolaidis, Anastasios, G. (ed.). The Unity of Plutarch's Work: Moralia themes in the Lives, Features of the Lives in the Moralia. Berlin-New York, 2008.

OliveIRA, Loraine: «O jovem Teseu: do reconhecimento paterno ao reconhecimento político", en GÓmez CARDó, Pilar, LEÃo, Delfim F. y De Oliveira Silva, Maria Aparecida (coords.). Plutarco entre mundos: visões de Esparta, Atenas e Roma. Coimbra, 2014, pp. 31-48.

Pelling, Christopher: "Plutarch's Method of Work in the Roman Lives". Journal of Hellenic Studies, 99 (1979), 74-96.

Pelling, Christopher: "Synkrisis in Plutarch's Lives", en Brenk, Frederick, y Gallo, Italo (eds.). Miscellanea Plutarchea (Atti del I convegno di studi su Plutarco, Roma, 23 novembre 1985). Ferrara, 1986, pp. 83-96.

Pelling, Christopher: "Childhood and Personality in Greek Biography", en Pelling, Christopher. Plutarch and History: Eighteen Studies. Swansea, 2002, pp. 301-338.

PleKet, Henri W: «Licht uit Leuven over de Romeinse jeugd?". Lampas, 12 (1979), 183-192.

Rawson, Beryl: Children and Childhood in Roman Italy. Oxford, 2003.

Roskam, Geert: «Educating the Young... over Wine? Plutarch, Calvenus Taurus, and Favorinus as Convivial Teachers", en Ribeiro FerreIRA, José, Leão, Delfim, Troster, Manuel y Barata Dias, Paula (eds.). Symposion and Philanthropia in Plutarch. Coimbra, 2009, pp. 369-383. 
Russell, Donald A.: Plutarch. London, 2001 [1ª ed., 1972].

SALLER, Richard P: "Pietas, Obligation, and Authority in the Roman Family", en Kneissl, Peter, y Losemann, Volker (eds.). Alte Geschichte und Wissenschaftsgeschichte: Festchrift für Karl Christ zum 65. Darmstadt, 1988, pp. 393-410.

SCIARrino, Enrica: "Schools, Teachers, and Patrons in Mid-Republican Rome", en Bloomer, Martin W. (ed.). A Companion to Ancient Education. Malden/Oxford/West Sussex, 2015, pp. 226-239.

SLUSANSKI, Dan: "Le vocabulaire latin des gradus aetatum". Revue Roumaine de Linguistique, 19 (1974), 103-121.

SOARES, Carmen: "Parent-Child Affection and Social Relationships in Plutarch: Common Elements in Consolation ad uxorem and Vitae", en NikOlaidis, Anastasios, G. (ed.). The Unity of Plutarch's Work: Moralia themes in the Lives, Features of the Lives in the Moralia. Berlin-New York, 2008, pp. 719-726.

SoARes, Carmen: Crianças e jovens nas Vidas de Plutarco. Coimbra, 2011.

SpÄTH, Thomas: "Cicero, Tullia, and Marcus: Gender-specific Concerns for Family Tradition?», en DASEN, Véronique, y SpäTH, Thomas (eds.). Children, Memory, and Family Identity in Roman Culture. Oxford, 2010, pp. 147-172.

Stone, Lawrence: The Family, Sex and Marriage in England 1500-1800. London, 1977 [hay trad. española, Familia, sexo $y$ matrimonio en Inglaterra 1500-1800. México, 1979].

Teodorsson, Sven-Tage: "The Education of Rulers in Theory (Mor.) and Practice (Vitae)", en Nikolaidis, Anastasios, G. (ed.). The Unity of Plutarch's Work: Moralia themes in the Lives, Features of the Lives in the Moralia. Berlin-New York, 2008, pp. 339-350.

Treggiari, Susan: "The Education of the Ciceros", en BloOmer, Martin W. (ed.). A Companion to Ancient Education. Malden/Oxford/West Sussex, 2015, pp. 240-251.

Tsouvala, Georgia: "Love and Marriage», en Beck, Mark (ed.). A Companion to Plutarch. Malden/Oxford/Chichester, 2012, pp. 191-201.

VelázQuez Fernández, Ana Esther: "Presencia y ausencia del educador en las Vidas de Plutarco", en Pérez Jiménez, Aurelio, y CASAdesús Bordoy, Francesc (eds.). Estudios sobre Plutarco: misticismo y religiones mistéricas en la obra de Plutarco: actas del VII simposio español sobre Plutarco (Palma de Mallorca, 2-4 de noviembre de 2000). Madrid, 2001, pp. 441-450.

Vuolanto, Ville: "Experience, Agency, and the Children in the Past. The Case of Roman Childhood", en LaEs, Christian, y Vuolanto, Ville 
(eds.). Children and Everyday Life in the Roman and Late Antique World. London, 2017, pp. 11-24.

Wiedemann, Thomas: Adults and Children in the Roman Empire. London, 1989.

Xenophontos, Sofía: "Plutarch", en Bloomer, Martin W. (ed.). A Companion to Ancient Education. Malden/Oxford/West Sussex, 2015, pp. 335-346.

Xenophontos, Sofía: Ethical Education in Plutarch. Moralising Agents and Contexts. Boston/Berlin, 2016. 